\title{
AVALIAÇÃO DO VIGOR DE SEMENTES DE FEIJÃO E DE SOJA POR MEIO DO TESTE DE FRIO
}

\section{MARCELO HISSNAUER MIGUEL}

Engenheiro Agrônomo

\author{
Orientador : Prof. Dr. SILVIO MOURE CICERO
}

\begin{abstract}
Dissertação apresentada à Escola Superior de Agricultura "Luiz de Queiroz", da Universidade de São Paulo, para obtenção do título de Mestre em Agronomia, Área de Concentração : Fitotecnia.
\end{abstract}

P I R A C I C A B A

Estado de São Paulo - Brasil

Dezembro - 1998 
Dados Internacionais de Catalogação na Publicação (CIP) DIVISÃO DE BIBLIOTECA E DOCUMENTAÇĀO - Campus "Luiz de Queiroz"/USP

Miguel, Marcelo Hissnauer

Avaliação do vigor de sementes de feijāo e de soja por meio do teste de frio / Marcelo Hissnauer Miguel. - - Piracicaba, 1998.

$63 \mathrm{p}$.

Dissertação (mestrado) - Escola Superior de Agriculara Luiz de Queiroz, 1998.

Bibliografia.

1. Feijão 2. Qualidade fisiológica 3. Semente 4. Soja 5. Teste de frio 6. Teste de vigor 1. Titulo

CDD 631.521 


\section{OFEREÇO}

A meus pais Paulo Tadeu e Welma pela confiança, carinho e amor.

$\grave{A}$ minhas irmãs Paula e Dani pela confiança, amizade e incentivo.

"Que DEUS me dê Serenidade para aceitar as coisas que não posso mudar, Coragem para mudar o que for possivel e Sabedoria para reconhecer a diferença".

"O poder da fé não tem limites. Porque a fé nos faz aliados de DEUS; e quem pode contar com a Aliança de DEUS, não conhece obstáculos e nem teme adversários".

"Quem crê de verdade não passa a vida lamentando a triste situação, mas colabora com DEUS para que as tristezas se transformem em alegrias".

\section{DEDICO}

À Mariane, fonte de inspiração e motivação. 


\section{AGRADECIMENTOS}

Ao professor Silvio Moure Cicero, orientador e amigo, pela dedicação e apoio em todas as fases do trabalho de dissertação e por muitas deferências recebidas ao longo do período de estudos.

Aos professores Júlio Marcos Filho, Walter Rodrigues da Silva, Ana Dionísia L. C. Novembre, pela amizade, apoio e valiosas sugestões.

À Engenheira Agrônoma Helena M. C. Pescarim Chamma e aos funcionários pelo auxilio constante prestado no Laboratório de Análise de Sementes, do Departamento de Agricultura da ESALQ/USP.

Aos funcionários do Departamento de Agricultura, em especial a Adriana A. T. Gimenez, Celestino A. Ferreira, Edson R. Teramoto, Edson A. Moraes e Ilze Helena C. de G. das Neves pela colaboração no desenvolvimento do presente trabalho.

Às Engenheiras Agrônomas Maria Heloísa D. Moraes e Marise C. Martins pelo auxilio na realização dos testes de sanidade de sementes e de análise solo e ao Prof. Dr. Hiroshi Kimati pelas valiosas sugestões.

Aos funcionários da Biblioteca Central, em especial a Eliana M. G. Sabino e Katia M. Andrade Ferraz, pelo auxilio prestado durante o curso.

À Denise Garcia Santana pela colaboração durante a análise estatística.

À Fundação de Amparo à Pesquisa do Estado de São Paulo (FAPESP) pela bolsa de estudos concedida. 
À EMBRAPA - Soja, em especial ao Dr. José de Barros França Neto e à CATI, em especial a Leila Martins e Maria Inês de Arruda Marianno, pelo fornecimento das sementes utilizadas na pesquisa.

À Escola Superior de Agricultura "Luiz de Queiroz" pela formação pessoal e profissional.

À E. P. Lawrie Agropecuária e Participações Ltda., em especial à pessoa do Dr. Michael Ferguson Smith, pela formação pessoal, profissional e constante apoio.

Ao professor e amigo Tomaz Caetano Canavan Rípoli pelo apoio e incentivo.

Aos colegas do Curso de Pós-Graduação, Mariane Victorio de Carvalho, Angélica Rodo, Cleiton Perleberg, Clóvis Peixoto, Cristina Ribeiro, Daniel Gentil, Leila Martins, Maria Cristina Spinola, Maristela Panobianco, Mônica Martins, Oscar Smiderle, Osmar Beckert, Renata Maschietto, Roseli Caseiro, Salvador Torres, Silvana Ohse, Prof. Dr. Francisco Amaral Villela e ao amigo André Kraide Monteiro pela amizade, auxilio, convivência saudável e aprendizado.

A todos que, direta ou indiretamente, colaboraram para que este trabalho pudesse ser realizado. 


\section{SUMÁRIO}

Página

RESUMO vii

SUMMARY ix

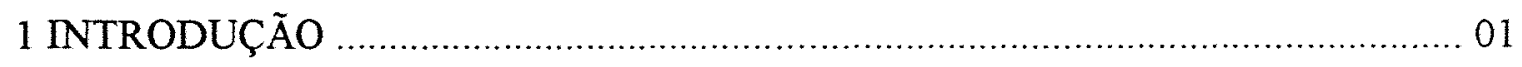

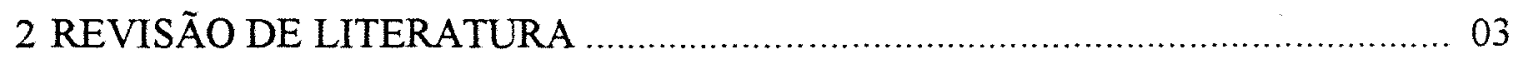

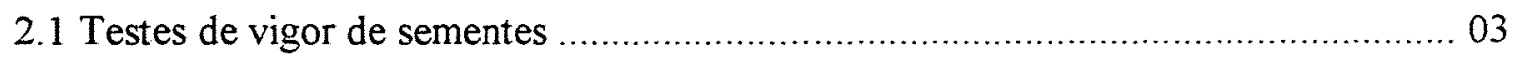

2.2 Testes de vigor mais utilizados para as sementes de feijão e de soja ...................... 06

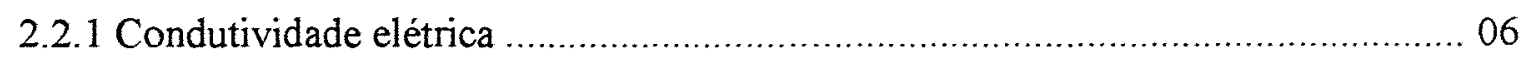

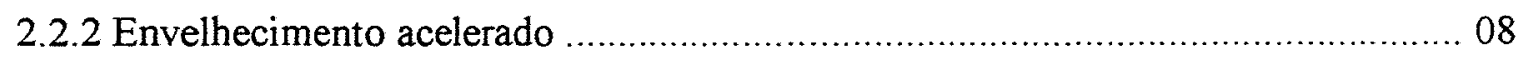

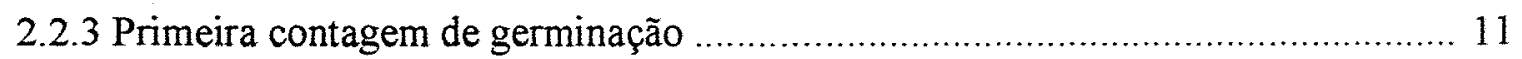

2.2.4 Emergência de plântulas em campo …………............................................... 12

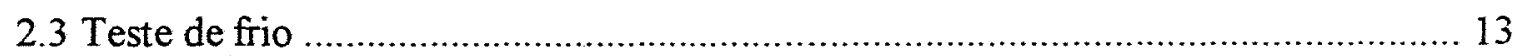

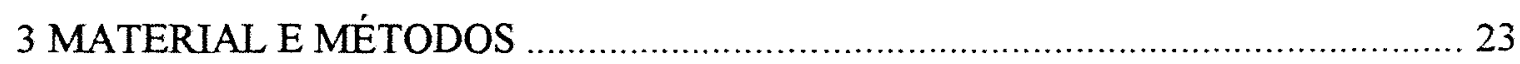

3.1 Metodologias utilizadas para o teste de frio .................................................... 23

3.1.1 Teste de frio com terra em caixas plásticas ................................................... 23

3.1.2 Teste de frio em rolo de papel com terra ..................................................... 24

3.1.3 Teste de frio em rolo de papel sem terra …………..................................... 25

3.2 Outras determinações utilizadas para avaliar a qualidade dos lotes de sementes ... 25

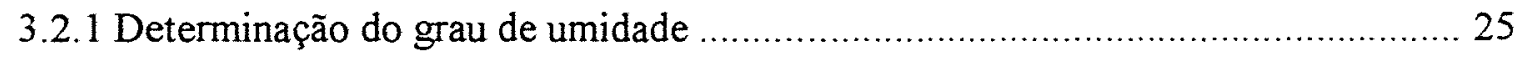

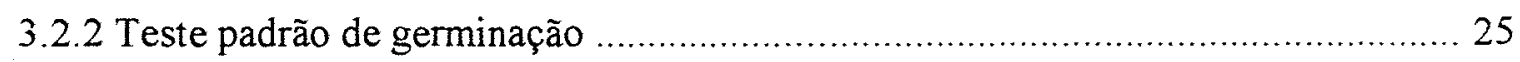

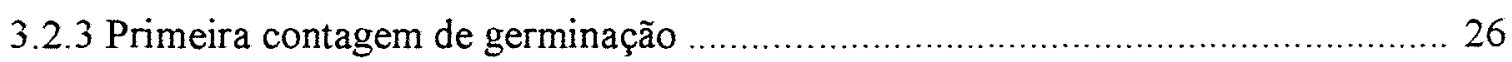

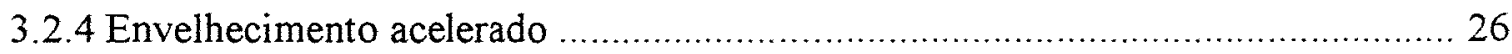

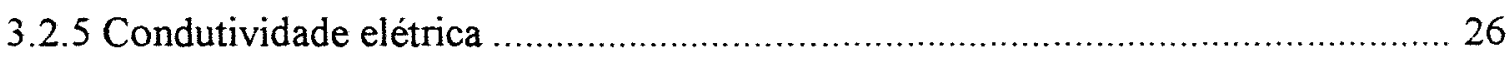

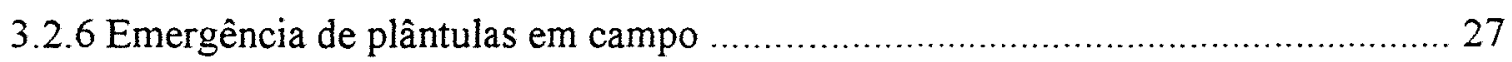

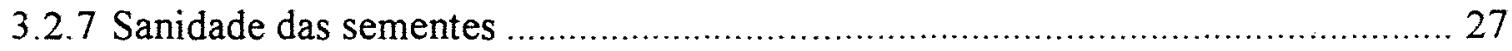

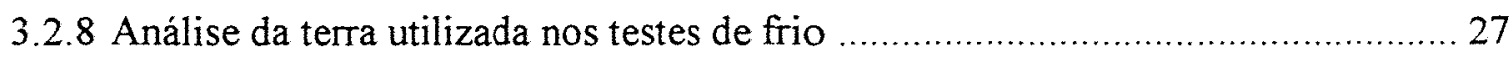




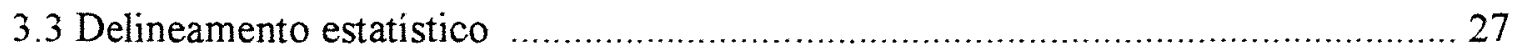

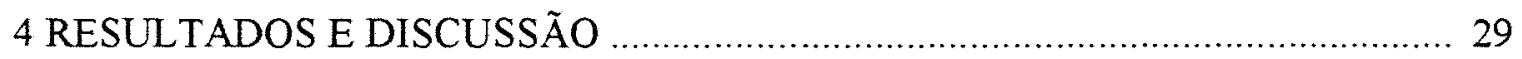

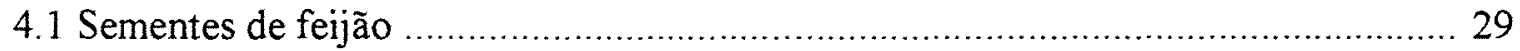

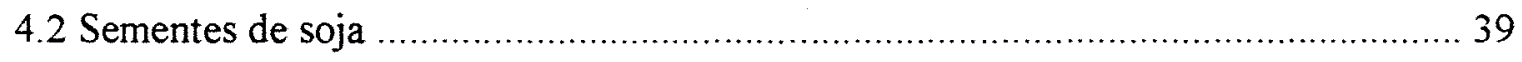

4.3 Considerações Gerais ....................................................................... 51

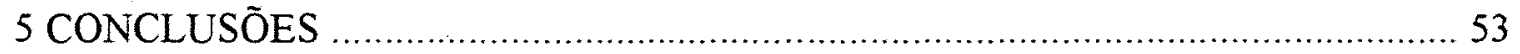

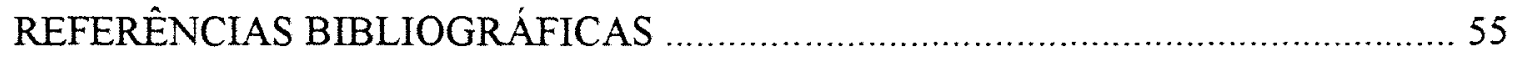




\title{
AVALIAÇÃO DO VIGOR DE SEMENTES DE FEIJÃO E DE SOJA POR MEIO DO TESTE DE FRIO
}

\author{
Autor : MARCELO HISSNAUER MIGUEL \\ Orientador : Prof. Dr. SILVIO MOURE CICERO
}

\section{RESUMO}

O trabalho foi desenvolvido no Laboratório de Análises de Sementes e em Área Experimental do Departamento de Agricultura da Escola Superior de Agricultura "Luiz de Queiroz", da Universidade de São Paulo, com o objetivo de estudar o desempenho das sementes de feijão e soja submetidas a diferentes metodologias do teste de frio, comparativamente a outros testes de vigor tradicionalmente utilizados para avaliar a qualidade fisiológica das sementes das referidas espécies. Para tanto, foram utilizados dois cultivares de feijão e três cultivares de soja provenientes de três lotes com diferentes qualidades fisiológicas para cada uma das espécies. Os testes de frio utilizados foram: em caixas plásticas com terra, em rolo de papel com terra e em rolo de papel sem terra. Para cada teste foram utilizadas variações de temperaturas de $10^{\circ} \mathrm{C}$ e $15^{\circ} \mathrm{C}$ e períodos de exposição ao frio, de três, cinco e sete dias. Os testes de laboratório constaram do teste padrão de germinação, primeira contagem de germinação, envelhecimento acelerado, condutividade elétrica e o de campo do teste de emergência de plântulas. Os testes foram conduzidos em duas épocas, espaçadas de quatro meses. As diferentes metodologias do teste de frio foram comparados pelo teste de Tukey e posteriormente foram estabelecidas correlações com os demais testes de vigor para as respectivas culturas. A análise dos dados e a interpretação dos resultados do presente trabalho permitiram concluir que, para sementes de feijão, as metodologias do teste de frio rolo de papel com terra, com períodos de 
exposição de cinco e, principalmente sete dias à $15^{\circ} \mathrm{C}$, proporcionaram condições favoráveis ao desenvolvimento de fungos, limitando suas utilizações e que o rolo de papel sem terra, nos períodos de três e cinco dias à $10^{\circ} \mathrm{C}$ e à $15^{\circ} \mathrm{C}$, proporcionaram melhores correlações com os demais testes de vigor, principalmente com a primeira contagem de germinação e emergência em campo. Para sementes de soja, as metodologias de caixa e de rolo de papel com terra, proporcionaram reduções drásticas na emergência das plântulas, principalmente para os materiais com qualidades fisiológicas mais baixas. As metodologias de rolo de papel sem terra apresentaram as melhores correlações com os testes de primeira contagem de germinação, condutividade elétrica e de emergência de plântulas em campo. 


\title{
EVALUATION OF VIGOUR BEANS AND SOYBEAN SEEDS BY COLD TEST
}

\author{
Author : MARCELO HISSNAUER MIGUEL \\ Adviser : Prof. Dr. SULVIO MOURE CICERO
}

\section{SUMMARY}

This research was conducted at the Seed Analysis Laboratory and Experimental Area of the Agricultural Department of the Escola Superior de Agricultura "Luiz de Queiroz" campus of the University of São Paulo. The objective was to study bean and soybean seeds development under different cold test methodologies compared to other traditional vigor tests used to evaluate physiological seed quality of the aforementioned species. Therefore, two bean cultivars and three soybean cultivars from three physiologically different lots of each species were used. Cold tests were carried out in: plastic boxes with soil, paper rolls with soil, and paper rolls without soil. For each test, temperatures from $10^{\circ} \mathrm{C}$ and $15^{\circ} \mathrm{C}$ and cold exposure of three, five and seven days were evaluated. Laboratory tests consisted of the standard germination test, first germination count, accelerated aging, electrical conductivity and seedlings emergence in the field. Tests were conducted during two seasons four months apart. The different cold test methodologies were compared by a Tukey test. Afterwards, correlations with the remaining vigor tests were established for the respective cultures. Data analysis and interpretation of the results allowed the conclusion that, for bean seeds, the cold test methodologies using paper rolls with soil and exposure for five and especially seven days at $15^{\circ} \mathrm{C}$ offered favorable conditions for fungus development, limiting their use; paper rolls without soil and exposure for three to five days at $10^{\circ} \mathrm{C}$ and $15^{\circ} \mathrm{C}$ correlated better with the remaining vigor tests, especially the first germination count and seedling 
emergence in the field. For soybean seeds, the methodologies using boxes and paper rolls with soil drastically reduced seedling emergence, especially in materials with low physiological quality. The methodologies using paper rolls without soil correlated best with the first germination count, electrical conductivity and seedlings emergence in the field. 


\section{INTRODUÇÃO}

Diversos segmentos do setor de produção de sementes de grandes culturas têm demonstrado grande interesse na utilização de testes de vigor para melhor avaliar a qualidade fisiológica das sementes. Estes testes têm como objetivo auxiliar os produtores de sementes a selecionar determinadas práticas que resultem na produção de sementes de melhor qualidade. Também, podem orientar os agricultores a selecionar os lotes de sementes a serem adquiridos e fornecer informações mais precisas sobre a densidade de semeadura.

O teste de frio é um dos testes de vigor mais utilizados em diversas regiões de clima temperado, onde a época de semeadura pode coincidir com períodos chuvosos e de baixa temperatura. É adotado, principalmente, nos Estados Unidos da América, Canadá e Europa. No Brasil apresenta-se com bom potencial de utilização na região sul do país.

Nesta região, nas épocas a partir de setembro até meados de outubro, não é de se estranhar a ocorrência de frentes frias chuvosas. Nestas condições, dependendo do nível de vigor dos lotes das sementes utilizadas, poderão resultar em grandes problemas de emergência de plântulas.

Nestas situações, o teste de frio pode funcionar como uma ferramenta de grande valor para uma seleção prévia dos lotes de sementes que apresentem maior potencial de emergência em solos frios e úmidos.

Seguindo essa linha de pensamento, as empresas produtoras de sementes de milho realizam este teste rotineiramente, obtendo-se excelentes resultados. No entanto, em outras grandes culturas, como soja, feijão, amendoim, algodão e outras, o teste de frio não tem sido muito utilizado, por falta de informações de pesquisa sobre o comportamento das sementes das referidas espécies nas condições em que o teste é 
conduzido. Diante do exposto, é possivel que, mediante metodologias específicas, o teste de frio possa ser utilizado com sucesso para outras espécies. Assim, o presente trabalho teve o objetivo de estudar o desempenho das sementes de feijão e de soja submetidas a diferentes metodologias do teste de frio, comparativamente a outros testes de vigor tradicionalmente utilizados para avaliar a qualidade fisiológica das sementes das referidas espécies. 


\section{REVISĀO DE LITERATURA}

\subsection{Testes de vigor de sementes}

Diferentes lotes de sementes com a mesma porcentagem de germinação no teste padrão, podem apresentar desempenhos diferentes sob condições desfavoráveis de campo (AOSA, 1983), fato que pode ser atribuído a diferenças de vigor existentes entre esses lotes.

Segundo CARVALHO (1986), a qualidade de um lote de semente poderia ser razoavelmente bem avaliada, usando o teste padrão de germinação, desde que o lote apresentasse alta homogeneidade. Entretanto, se o lote apresentar alto grau de heterogeneidade, o teste padrão de germinação apresentaria baixa sensibilidade e, nesse caso, os testes de vigor representariam melhor o desempenho do lote no campo.

Ainda, segundo CARVALHO e NAKAGAWA (1988), se as condições de campo forem favoráveis, os resultados de germinação apresentam alta correlação com a emergência em campo; porém, estas condições ideais nem sempre estão presentes quando os agricultores estão realizando seus plantios.

Isso pode ser explicado pelo fato de que as principais alterações nos processos bioquímicos, associados a deterioração, geralmente ocorrem antes que se verifique o declinio na capacidade de germinação (MATTHEWS, 1981). Assim, essas sementes podem apresentar diferenças de vigor porque apresentam-se em diferentes estádios de deterioração, cuja manifestação precede a queda de poder germinativo.

De acordo com DELOUCHE (1981), citado por LUCENA, 1995, o teste padrão de germinação apresenta dentre várias limitações, três principais, sendo a primeira pelo fato de que o teste padrão de germinação é destinado a obter a mais elevada porcentagem possivel de plântulas normais, uma vez que possui um período de 
execução prolongado e as condições especificas do teste são favoráveis. Dessa forma, sem a ocorrência de estresse e com um período bastante longo, as sementes fracas também conseguem germinar e produzir plântulas normais. A segunda limitação está na avaliação, a qual classifica as plântulas em normais e anormais, apenas pelo critério morfológico, como por exemplo na presença ou ausência de vários órgãos, fraturas e danos. Não há durante a interpretação do teste, critérios para avaliação quanto a diferenças fisiológicas, tais como, a velocidade e uniformidade de germinação, taxa de crescimento de plântulas, e outros. Em terceiro lugar, não menos importante que as duas primeiras, consiste em que a perda da capacidade germinativa e de produzir uma plântula normal, ocorre no estádio final da deterioração da semente, pois antes de atingir este estádio, muitas mudanças que prejudicam o desempenho da semente no campo ou no armazenamento já ocorreram.

Dessa forma, um dos principais desafios das pesquisas sobre testes de vigor tem sido o de caracterizar parâmetros adequados, comuns à deterioração das sementes, de modo que, quanto mais distante da perda de capacidade de germinação estiver o parâmetro empregado, mais sensivel será o teste, complementando, assim, as informações fornecidas pelo teste padrão de germinação (AOSA, 1983).

$\mathrm{Na}$ literatura podem ser encontradas várias definições de vigor, como: vigor de sementes é a soma das propriedades que determinam o potencial de atividade e desempenho de uma semente ou de um lote de sementes durante a germinação e a emergência da plântula (INTERNATIONAL SEED TESTING ASSOCIATION - ISTA, 1995b), ou, vigor de sementes compreende às propriedades, que determinam o potencial para uma emergência rápida e uniforme de plântulas normais sob ampla faixa de condições ambientais (ASSOCIATION OF OFFICIAL SEED ANALYSTS, 1995b AOSA, 1983), ou ainda, vigor de sementes é o nível energia que uma semente dispõe para realizar as tarefas do processo germinativo (CARVALHO, 1986).

A primeira manifestação por escrito, de vigor de sementes, foi efetuada por NOBBE, na Alemanha em 1876, citado por CARVALHO (1986). No entanto, o primeiro teste foi descrito por HILTNER, em 1911. No final da década de 30 foram 
desenvolvidos trabalhos sobre o teste de tetrazólio na Alemanha e, simultaneamente, sobre o teste de frio em milho nos Estados Unidos da América (CARVALHO, 1986).

Entretanto, somente a partir da década de 60 , as pesquisas tiveram grande impulso e desde então vários testes de vigor tem sido propostos (GRABE, 1973). Por outro lado, quanto a uma definição de vigor de sementes, várias tentativas foram efetuadas, porém sempre foram questionadas por deixarem de incluir algum aspecto em sua manifestação (MARCOS FILHO et al., 1987).

Vários autores propuseram classificações para os testes. Dentre eles, ISELY (1957) classificou-os em diretos e indiretos, onde os primeiros tentavam simular ambientes de campo em laboratório. Nesse caso, as sementes mostram a sua habilidade de emergir sob condições simuladas de estresse no campo. Nos métodos indiretos, os testes medem determinados atributos fisiológicos ou certas características estruturais das sementes indiretamente relacionadas ao vigor. POLLOCK e ROOS (1972) optaram por classificar em testes rápidos e testes que reproduzem condições de estresse.

WOODSTOCK (1973) classificou em testes fisiológicos e bioquímicos, e McDONALD (1975) acrescentou a essa classificação os testes físicos. Independentemente da classificação a ser adotada, a pesquisa em análise de sementes visa a obtenção de testes de vigor que tenham alta reprodutibilidade e sejam rápidos, não onerosos, de fácil execução, objetivos e indicativos do potencial de emergência das plântulas em campo (McDONALD, 1975).

Baseando-se nesses aspectos, de acordo com CARVALHO (1986), somente alguns testes foram considerados mais indicados, tanto pela ISTA, citado por FIALA (1981), e pela AOSA (1983), sendo eles o de condutividade elétrica, de envelhecimento acelerado, do crescimento da plântula, da classificação do vigor de plântulas, de tetrazólio e de frio. 


\subsection{Testes de vigor mais utilizados para as sementes de feijão e de soja}

\subsubsection{Condutividade elétrica}

Originariamente desenvolvido para detectar as causas de baixa emergência em campo de lotes de sementes de ervilha rugosa, que apresentavam elevado potencial de germinação em laboratório, vem sendo atualmente considerado como um teste que apresenta bom potencial em termos de padronização, pela sua facilidade de execução e rapidez na obtenção de resultados.

É baseado no conceito de que, quando as sementes são imersas em água, as de baixo vigor liberam maior quantidade de eletrólitos na solução, refletindo a perda de integridade das membranas celulares (WOODSTOCK, 1973; GRABE, 1976) e, consequentemente, a redução do vigor. Portanto, a condutividade elétrica da solução de embebição de sementes é utilizada como um teste para avaliar o vigor (AOSA, 1983; MARCOS FILHO et al., 1987), visto que o valor da condutividade elétrica é função da quantidade de lixiviados na solução, a qual está diretamente relacionada com a integridade das membranas celulares.

Segundo ABDUL-BAKI (1980), a organização do sistema de membranas é máxima na maturidade fisiológica das sementes. Após a maturidade fisiológica, a semente atinge uma condição de baixo teor de água, que é variável em função das condições ambientais, principalmente da umidade relativa do ar. Com a secagem das sementes, as membranas celulares sofrem um processo de desorganização estrutural, estando tanto mais desorganizadas quanto menor for o teor de água nas sementes (BEWLEY, 1986), e, em conseqüência, verifica-se um aumento no grau de lixiviação, principalmente quando esse teor é inferior a $11 \%$. Esses resultados têm sido constatados com sementes de soja e feijão (TAO, 1978b; LOEFFLER et al., 1988; HAMPTON et al., 1992).

Quando uma semente seca é colocada para embeber água, verifica-se uma rápida embebição no início, associada a lixiviação de eletrólitos do interior das células para o meio externo. Consequentemente, é provável que a permeabilidade seletiva das 
membranas do tonoplasto e plasmalema, que normalmente retém os solutos dentro da célula, tenham perdido a integridade durante a secagem e não atuem como uma barreira de restrição durante o estádio inicial de embebição (BEWLEY \& BLACK, 1985).

Em função dessa desorganização das membranas celulares, as sementes sofrem um processo de redução e perda de vigor, fato esse diretamente relacionado com o aumento da quantidade de lixiviados liberados na água de embebição, ou seja, existe uma relação inversa entre a perda de lixiviados e o vigor de semente, baseada, principalmente, na perda da integridade de membranas e de constituintes celulares (WOODSTOCK, 1973; MARCOS FILHO et al., 1990), citados por VIEIRA \& CARVALHO (1994).

Segundo HEPBURN et al. (1984) o teste de condutividade elétrica tem se mostrado bastante promissor para espécies de sementes graúdas como ervilha, feijão e soja, em várias localidades. As pesquisas têm mostrado que o decréscimo na germinação e no vigor é diretamente proporcional ao aumento da lixiviação de solutos, indicando que a condutividade elétrica é um método eficiente para a avaliação do vigor, sendo considerado um indicador eficiente da emergência de plântulas em campo.

O teste é considerado promissor em termos de padronização, porém, o Comitê de Vigor da ISTA constatou variações nos resultados entre laboratórios devido a problemas de metodologia (PERRY, 1981). A pesquisa tem demonstrado que vários fatores podem afetar o resultado do teste, tais como: qualidade da água, temperatura e duração do período de embebição, grau de umidade e número de sementes testadas (TAO, 1978b). BEDFORD (1974) acrescentou a estes fatores, o genótipo. Para ROWLAND \& GUSTA (1977), citado por DIAS (1994), a liberação de eletrólitos de sementes de leguminosas resulta da interação de três fatores principais: cultivar, grau de umidade da semente e temperatura de embebição.

MARCOS FILHO et al. (1985) pesquisando sementes de soja colhidas em diferentes épocas e armazenadas em ambientes distintos, concluíram que o conjunto de informações proporcionadas pelos testes de germinação, envelhecimento artificial e condutividade elétrica foi eficiente para diferenciar os níveis de qualidade fisiológica das sementes e estimar o potencial de emergência das plântulas em campo, com destaque 
para o teste de condutividade que permitiu a obtenção de informações mais precisas. Em concordância, BARROS (1988) realizando um estudo comparativo entre testes para avaliação da viabilidade e vigor de sementes de soja, ressaltou a eficiência da condutividade na identificação de lotes com diferentes niveis de qualidade e potencial de emergência em campo. Ainda, NASCIMENTO \& CICERO (1991), avaliando a qualidade fisiológica de sementes de ervilha submetidas a diferentes tratamentos fungicidas, constataram alterações no vigor durante o armazenamento através da condutividade.

BROUWER e MULDER (1982) utilizando o teste de condutividade elétrica em sementes de feijão, observaram ser este um método rápido para detectar a baixa qualidade de lotes de sementes e ao mesmo tempo complementar as informações obtidas pelo teste de germinação na avaliação do potencial de desempenho das sementes no campo. Ainda, RODRIGUES (1995), trabalhando com sementes de feijão vagem, constatou que este teste é adequado para separação eficiente dos lotes de sementes em diferentes niveis de qualidade, além de predizer a emergência em campo.

\subsubsection{Envelhecimento acelerado}

É um dos testes mais utilizados para a avaliação do vigor de sementes. É baseado no fato de que a taxa de deterioração de sementes aumenta consideravelmente através da sua exposição a condições adversas de temperatura e umidade relativa do ar. Nessas condições, as sementes de baixa qualidade deterioram-se mais rapidamente quando comparadas àquelas mais vigorosas, possibilitando, dessa forma, estabelecer diferenças no potencial fisiológico das amostras avaliadas (MARCOS FILHO, 1994).

O teste foi desenvolvido por DELOUCHE (1965), na tentativa de determinar o potencial relativo de armazenamento de lotes de trevo e de festuca. Este estudo baseou-se em informações obtidas por CROKER e GROVES (1915), segundo os quais a morte das sementes durante o armazenamento foi causada pela coagulação de proteínas e que o aquecimento a alta temperatura acelerou este processo. Os autores sugeriram que os testes de germinação conduzidos após a exposição de sementes secas 
à temperaturas elevadas $\left(50-100^{\circ} \mathrm{C}\right)$, por breves períodos, poderiam ser úteis para predizer a longevidade.

Em 1962, HELMER et al. relataram que a resposta germinativa de sementes de trevo após vários dias de exposição à alta temperatura $\left(35-40^{\circ} \mathrm{C}\right)$ e umidade relativa do ar (100\%), foi fortemente associada com o vigor das sementes e emergência das plântulas em campo, sugerindo que o envelhecimento acelerado poderia ser útil para avaliação do potencial relativo de armazenamento de lotes de sementes. Esta sugestão foi considerada por vários pesquisadores, sendo então desenvolvida uma série de pesquisas envolvendo o teste.

Atualmente, o teste de envelhecimento acelerado é utilizado para avaliar o vigor de sementes de diversas espécies, tais como soja (TOMES et al., 1988; EGLI et al., 1990), feijão (HAMPTON et al., 1992), sorgo (IBRAHMM et al., 1994), trigo (TOMER \& MAGUIRE, 1990), amendoim (VANZOLNI et al, 1997) e milho (TEKRONY et al., 1989; BITTENCOURT \& VIEIRA, 1997) e, incluído em programas de controle de qualidade por empresas produtoras de sementes, pois, em poucos dias, pode-se ter uma estimativa do potencial de armazenamento dos lotes processados.

Em se tratando de sementes de leguminosas, e também de trigo e milho, MATTHEWS (1985), GANGULI e SEM-MANDI (1990), LIN (1990) e BASAVARAJAPPA e SHETTY (1991), citados por MARCOS FILHO (1994), concluíram que a exposição das sementes à temperatura e umidade elevadas provoca sérias alterações degenerativas no metabolismo das sementes (desnaturação de proteínas, queda nos teores de carboidratos totais, de açúcares redutores, de proteinas solúveis e de fosfato, aumento no teor de ácidos graxos, desestabilização da atividade de enzimas) desencadeadas pela desestruturação e perda de integridade do sistema de membranas celulares, causadas, principalmente, pela peroxidação de lipídeos (constituintes essenciais da membrana). Assim, esses eventos promovem descontrole do metabolismo e das trocas de água e solutos entre a célula e o meio exterior, determinando a queda da viabilidade da semente. A manifestação inicial, como a menor velocidade de germinação, é correspondente aos primeiros indícios de desestruturação das membranas, enquanto a ocorrência de anormalidades nas plântulas, nos estádios finais de 
deterioração, é determinada pela morte de tecidos importantes, em diferentes regiões da semente.

O teste de envelhecimento acelerado apesar de uma boa aceitação entre os tecnologistas e analistas de sementes e, também dos produtores, quanto a sua padronização, deve ser cuidadosamente executado, pois vários fatores são capazes de contribuir para a falta de consistência dos resultados.

Um dos principais fatores que influenciam os resultados do teste é a temperatura, que oscila entre $41^{\circ} \mathrm{C}$ e $45^{\circ} \mathrm{C}$ (ISTA, 1995a). A sua elevação promove efeitos mais drásticos sobre a germinação do que o prolongamento do período de envelhecimento (TOMES et al, 1988). Assim, torna-se necessário um constante monitoramento da temperatura durante o teste, para que sejam obtidos resultados confiáveis.

Outro fator de variação é o número de horas requeridas para o teste. É um fator que tem sido estudado intensamente, mas não há ainda consenso entre os pesquisadores quanto aos periodos de envelhecimento mais adequados para sementes de várias espécies.

A ação de fungos associados às sementes pode ser considerada uma das causas responsáveis pela variabilidade de resultados. A presença de patógenos, particularmente Aspergillus spp., pode interferir negativamente no desempenho das sementes envelhecidas artificialmente.

MARCOS FILHO (1994) ressaltou que temperatura e umidade elevadas podem inibir a manifestação de alguns microrganismos; assim, os dados obtidos no teste de envelhecimento podem ser superiores aos observados no teste de germinação com as mesmas amostras. Portanto, as condições impostas pelo teste de envelhecimento artificial não agiriam apenas no comportamento das sementes, mas, também, influenciariam na ação de microrganismos participantes da deterioração. A peroxidação de lipídios em sementes envelhecidas de soja e ervilha, ao provocar maior liberação de aldeídos voláteis, estimula a germinação de esporos de fungos presentes durante a germinação das sementes (HARMAN et al., 1982). 
Atualmente, o teste de envelhecimento acelerado é considerado padronizado somente para avaliação do vigor de sementes de soja. No entanto, excelentes progressos têm sido realizados no refinamento de técnicas e na avaliação das interações entre período de exposição, temperatura e grau de umidade das sementes, que poderão tornar possivel, portanto, a padronização da metodologia para outras espécies.

\subsubsection{Primeira contagem de germinação}

Consiste em registrar a porcentagem das plântulas normais constatada na data referente a primeira contagem do teste padrão de germinação, estabelecida pelas Regras para Análise de Sementes (1992).

Indiretamente, está se realizando uma avaliação da velocidade de germinação, pois, uma maior porcentagem de plântulas normais na primeira contagem do teste de germinação, significa que as sementes desta amostra germinaram mais rapidamente que as demais. Este teste pode, muitas vezes, expressar melhor as diferenças de velocidade de germinação entre lotes do que os índices de velocidade de germinação (NAKAGAWA, 1994).

Segundo MATTHEWS (1985), no processo de deterioração, a velocidade de germinação decresce antes da porcentagem de germinação e, portanto, os lotes que germinam mais rapidamente, apresentam valores mais elevados de germinação na primeira contagem e podem ser consideradas mais vigorosas do que aquelas de germinação mais lenta.

De acordo com a AOSA (1983) este teste apresenta vantagens importantes, para a sua utilização em laboratório de sementes, pois é um teste barato, relativamente rápido, não requer equipamentos especializados, nem treinamento tecnológico adicional.

No entanto, o referido teste tem sido criticado como teste de vigor, devido a fatores variáveis como umidade e temperatura, que são dificilmente padronizados entre laboratórios e influenciam a velocidade de germinação, além de depender da habilidade 
do analista, em possuir conceitos bem claros de uma semente germinada (McDONALD, 1975; AOSA, 1983).

MARCOS FILHO et al. (1984), trabalhando com sementes de soja, analisaram a relação entre vários testes para a avaliação do vigor de sementes e emergência das plântulas em campo; consideraram os testes de germinação, primeira contagem de germinação e velocidade de germinação, como os mais eficientes para identificar diferenças entre o potencial de emergência das plântulas. De forma semelhante MOTTA (1986), realizando um estudo comparativo entre testes de vigor com a emergência das plântulas em campo, com sementes de soja, obteve correlações significativas entre os resultados da primeira contagem de germinação e a emergência em campo, demonstrando a sua eficiência.

MORENO (1986), entretanto, constatou que esse teste não demonstrou sensibilidade para diferenciar níveis de qualidade de sementes de milho, quando comparado a outros testes de vigor, como o teste de frio e o de envelhecimento acelerado.

\subsubsection{Emergência de plântulas em campo}

Este teste visa avaliar ou determinar o vigor relativo do lote de sementes, através da porcentagem de emergência de plântulas em condições de campo.

Parte do princípio de que lotes que apresentam um maior percentual de sementes em condições de germinar e originar plântulas com capacidade de emergir do solo, em condições não controladas de campo, são os mais vigorosos. Enquanto que, as sementes pouco vigorosas não apresentariam resultados semelhantes.

Quando esse teste é conduzido próximo a época normal de semeadura, fornece boas informações quanto a quantidade de sementes a ser utilizada, visando uma população adequada; no entanto, quando conduzido em épocas, onde as condições climáticas são inadequadas a semeadura, poderá fornecer resultados que gerem subsídios suficientes para a comparação e diferenciação de lotes (NAKAGAWA, 1994). 
Devido às variações ambientais encontradas entre diferentes locais, no decorrer do ano, a comparação de resultados entre localidades distintas é dificultada, ocorrendo muitas vezes resultados controversos (PERRY, 1981). Com o objetivo de reduzir o efeito do ambiente, é necessário que o local escolhido para a condução do teste não apresente problemas de patógenos e pragas de solo, o que certamente irá interferir no processo de germinação e emergência das plântulas.

\subsection{Teste de frio}

O desempenho fisiológico das sementes, é influenciado diretamente, pelas condições ambientais, por ocasião da semeadura. Portanto, esta operação deve ser realizada em épocas que propiciem um desenvolvimento adequado das sementes, ou seja, em um período em que as sementes tenham condições de expressar o seu real potencial.

No entanto, sabe-se que, muitas vezes, por ocasião da semeadura, as condições ambientais predominantes não são as ideais para que as sementes se desenvolvam de maneira adequada. Portanto, a avaliação da qualidade de um lote de sementes que será submetido à condições adversas, fornecida pelo teste padrão de germinação, não irá representar o real desempenho das sementes no campo. Diante desta situação, o uso de testes que forneçam condições semelhantes às encontradas no campo, seriam de grande utilidade, permitindo assim, verificar o desempenho de diferentes lotes sob condições adversas.

Dentre os testes desenvolvidos com o objetivo de fornecer resultados complementares ao do teste padrão de germinação, pode-se citar o teste de frio, cujo princípio baseia-se na avaliação da qualidade de sementes sob condições adversas. É considerado um teste de resistência, ou seja, o lote de sementes que melhor resistir às condições adversas é considerado mais vigoroso. De forma geral, se os resultados do teste de frio se aproximarem dos obtidos no teste padrão de germinação, há grande possibilidade desse lote apresentar capacidade para germinar sob ampla variação das condições de conteúdo de água e temperatura do solo (CICERO e VIEIRA, 1994). 
O teste de frio foi inicialmente desenvolvido para simular as condições de alta umidade e baixa temperatura que prevaleciam no "cinturão do milho", nos Estados Unidos da América, por ocasião da semeadura (KRZYZANOWSKI et al., 1991a). A presença de certos patógenos nestas condições afeta a germinação, o crescimento e a emergência de plântulas. Com isso, o teste de frio passou a ser conduzido incluindo-se a utilização de solo como substrato.

Atualmente, o teste de frio é o mais empregado na avaliação do vigor de sementes de milho e estudos vem sendo desenvolvidos para adequá-lo a outras espécies, que não necessariamente sejam cultivadas em condições semelhantes as encontradas no "cinturão do milho", pois o objetivo é que seja utilizado como teste de rotina em laboratórios de análise de sementes na avaliação da qualidade fisiológica (CICERO e VIEIRA, 1994).

No Brasil, KRZYZANOWSKI et al. (1991b), relataram que para os estados do sul, onde lavouras de algodão, milho e soja podem ser semeadas a partir de setembro a meados de outubro, o teste de frio parece ser bastante promissor, devido ao alto potencial de utilização, pois nesta época a região está sujeita a ocorrência de frentes frias chuvosas, as quais, dependendo do nível de vigor dos lotes, poderão resultar em sérios problemas de germinação e emergência de plântulas. Nestas condições, o teste de frio pode funcionar como um instrumento de grande valor para a seleção prévia de lotes de sementes que apresentam bom potencial de emergência em solos frios e úmidos.

No início, a metodologia do teste de frio era realizada utilizando-se solo como substrato. No entanto, com o passar do tempo, vem sofrendo algumas alterações em busca de uma melhor adequação; uma vez que o uso de solo não permite uma padronização entre laboratórios, devido a características variáveis do solo, como propriedades química, fisica e biológica, além de tornar o teste mais trabalhoso (BURRIS e NAVRATL, 1979).

Dentre as metodologias alternativas desenvolvidas para o teste de frio, pode-se destacar o rolo de papel sem terra, rolo de papel com terra e metodologia em bandeja. É importante ressaltar que o uso de uma ou outra metodologia deve ser baseado 
em resultados cientificos que demonstrem qual seria a mais adequada na avaliação do vigor de lotes para uma determinada espécie e que possibilitasse a sua padronização.

Além do uso de uma metodologia adequada, vários são os fatores que podem afetar os resultados fornecidos pelo teste de frio, entre eles pode-se citar: período de exposição das sementes à baixas temperaturas, temperatura utilizada, umidade do substrato e a proporção areia/terra. É importante ressaltar mais uma vez que, sementes de diferentes espécies e cultivares podem apresentar comportamento variável quando expostas à condições adversas (CICERO e VIEIRA, 1994).

Dentre os fatores mais estudados, devido a serem os mais determinantes nas variações de resultados, destacam-se a temperatura, a umidade do substrato, a variabilidade de substrato, a espécie e o genótipo em estudo.

CROSIER (1957), sugeriu que, devido a variabilidade dos solos, temperatura, umidade, tipos de recipientes e duração do teste, este deveria ser ajustado a cada laboratório, com a utilização de um lote conhecido, para a obtenção de resultados mais uniformes.

A temperatura do teste de frio geralmente recomendada é de $10^{\circ} \mathrm{C}$ (CICERO \& VIEIRA, 1994). Já, na Holanda, a temperatura de $8,5^{\circ} \mathrm{C}$ é freqüentemente usada (NIJENSTENN, 1985). BRUGGINK et al. (1991) reportaram que diferenças de vigor podem ser detectadas à temperaturas entre 8,5 a $13,5^{\circ} \mathrm{C}$, mas as diferenças são mais marcantes à temperaturas mais baixas.

A temperatura de $8,8^{\circ} \mathrm{C}$ e um curto período de frio (três dias), foram mais efetivos para detectar diferenças de vigor entre os lotes do que temperaturas entre $8,8^{\circ} \mathrm{C}$ e $15^{\circ} \mathrm{C}$; porém acima de $15^{\circ} \mathrm{C}$ diferenças não foram detectadas. À baixa temperatura, a germinação é atrasada e a semente fica exposta ao ataque de microrganismos, sendo que estes influenciam nos resultados do teste de frio com terra.

Ainda, a umidade e a temperatura do solo afetam a severidade das doenças causadas por espécies de Rhizoctonia (WONG et al., 1984) e Fusarium (NIJENSTEIN, 1995). 
A umidade do substrato tem influência sobre o desenvolvimento de fungos nas sementes. Em um trabalho realizado por WOLTZ (1997), com sementes não tratadas de milho, constatou-se que houve uma queda de $48 \%$ na germinação das sementes submetidas a diferentes umidades no substrato. Constatou-se ainda que esse efeito não foi tão pronunciado para sementes tratadas.

Estudando a capacidade de retenção de água no substrato, em teste de frio utilizando terra, TAO (1978a) obteve maiores correlações com a emergência em campo quando essa capacidade foi de $52 \%$ e menores quando utilizou $42 \%$, para sementes de soja. Observou ainda, que a utilização de substrato esterilizado permitiu uma maior emergência de plântulas, confirmando a influência dos microrganismos nos resultados do teste. Resultado semelhante foi obtido por WOLTZ (1997), onde se verificou um aumento na germinação de sementes de milho, submetidas ao teste de frio com o uso de sementes tratadas e uso de solo esterilizado, concluindo-se que os patógenos do solo tem grande efeito sobre a germinação no teste de frio.

BURRIS e NAVRATL (1979) compararam várias metodologias do teste de frio usadas em nove laboratórios de análise de sementes e também encontraram grande variação nos resultados. Os valores médios variaram de $74 \%$ (terra em caixa) para 93\% (método da bandeja) sobre os 60 lotes de sementes de milho que foram testados. Como exemplo, os autores citam o lote 3 da variedade W153R que teve uma germinação de $38 \%$ quando avaliada por um laboratório e de $96 \%$ quando avaliada por outro, sendo que ambos utilizaram a mesma metodologia que foi a de terra em caixa, recomendada pela AOSA. O mais baixo coeficiente de variação $(1,99 \%)$ foi obtido com o método da bandeja.

Um estudo da variabilidade do teste de frio (rolo de papel com terra, caixa e bandeja) dentro e entre laboratórios e depois comparando-os com os resultados do teste padrão de germinação, permitiu observar que as variações do teste de frio não foram maiores do que as obtidas no teste padrão de germinação. Dessa forma, BYRUM e COPELAND (1995), concluíram que os resultados deste teste de vigor poderiam ser utilizados com as mesmas tolerâncias dos resultados do teste padrão de germinação. A 
variabilidade no teste de frio foi reduzida dentro de cada laboratório onde os métodos podem ser padronizados.

O Comitê de vigor da ISTA (ISTA, 1995a) conduziu vários testes de aferição e encontrou resultados variáveis entre as metodologias do teste de frio. Entretanto, os métodos de rolo de papel e bandeja foram os que apresentaram maior reprodutibilidade de resultados. Para fins de utilização, as empresas de sementes dos Estados Unidos da América têm estabelecido uma diferença mínima de 5 a $15 \%$ entre o teste de frio e o teste padrão de germinação; se a diferença for abaixo desta faixa, o lote de sementes deve ser usado somente em áreas onde as condições ambientais para a emergência sejam favoráveis (CAMPOS, 1998).

O teste de frio em rolo de papel toalha com terra foi mais severo para detectar injúrias causadas por secagem em sementes de milho, mas houve algumas variações em função do substrato (LOEFFLER et al., 1985). Porém, quando foi utilizado o mesmo método sem terra, houve menos variabilidade. Ambos os testes detectaram redução na porcentagem de germinação associada com as injúrias de secagem. Devido às complicações encontradas no uso do teste com terra e similaridade obtida em ambos os testes para a detecção de danos por secagem, os autores concluíram que o teste de frio sem terra é aceitável para ser utilizado em estudos com secagem de sementes de milho, por ser sensivel, fornecer resultados com alta reprodutibilidade e também pela simplicidade.

MOLINA et al. (1987), visando avaliar diferentes metodologias do teste de frio na caracterização fisiológica das sementes de milho, concluíram que, embora o teste de frio tradicional (terra + areia), seguindo a metodologia descrita por BASKIN, citado por POPINIGIS (1985), onde foi utilizada a temperatura de 7 à $10^{\circ} \mathrm{C}$ por sete dias, tenha sido a que permitiu diferenciar melhor os niveis de qualidade entre os lotes estudados, nele, a emergência de plântulas foi mais afetada do que outros. As outras metodologias testadas envolveram o substrato Germitest e duas variantes relativas à temperatura e ao tempo de exposição, sendo uma à $10^{\circ} \mathrm{C}$ por cinco dias e outra 7 à $10^{\circ} \mathrm{C}$ por sete dias. Os testes de frio modificados mostraram ser menos eficientes para detectar 
as diferenças de qualidade, embora o uso de frio por sete dias $\left(7\right.$ à $\left.10^{\circ} \mathrm{C}\right)$ permitiu estabelecer uma melhor separação dos níveis de qualidade entre os lotes.

$O$ teste de frio usando rolo de papel com terra, mantidos a temperatura de $8^{\circ} \mathrm{C}$ por sete dias e depois colocados em ambiente à $20^{\circ} \mathrm{C}$ por oito dias (FIALA, 1987), mostrou-se eficiente como teste de vigor para feijão-fava e ervilha. Embora existam diferenças significativas entre os laboratórios, a classificação dos lotes não diferiu e os resultados do teste foram significativamente relacionados com a emergência em campo na maioria dos locais estudados. É também possivel que diferenças entre plântulas vigorosas e não vigorosas se tornassem mais evidentes se o período do teste fosse prolongado. Para o milho, a classificação dos lotes foi similar em todas as estações (os resultados tiveram alta reprodutibilidade), mas a relação entre o teste de frio e a emergência em campo foi baixa (FIALA, 1987).

Comparando dois testes de frio modificados (rolo de papel com terra à $10^{\circ} \mathrm{C}$ por cinco dias e 7 à $10^{\circ} \mathrm{C}$, por sete dias) MOLINA et al. (1987), observaram resultados bem similares, porém bastante diferentes quando comparados ao teste tradicional (terra e areia, 7 à $10^{\circ} \mathrm{C}$, por 7 dias), que foi o melhor método para detectar diferenças de qualidade fisiológica em sementes de milho (condições mais drásticas parecem ser mais eficientes para detectar essas diferenças). Materiais híbridos quando comparados com os de polinização livre, apresentaram um melhor desempenho nos testes modificados, indicando uma associação entre cultivares e condições do teste

BURRIS e NAVRATIL (1979), estudando procedimentos empregados por diversos laboratórios na condução do teste de frio com sementes de milho, constataram que a menor variação para o método foi obtida com a utilização de rolos de papel com uma pequena quantidade de terra. LOEFFLER et al. (1985) sugeriram a eliminação da terra do teste para minimizar ainda mais a variabilidade dos resultados. Ainda, segundo LOEFFLER et al. (1985), o teste de frio, sem a utilização de terra, avalia diretamente os efeitos de baixa temperatura e alto teor de água nas sementes, sem a interferência de outros fatores. Nesse caso não existe a microbiota do solo, o que facilita a padronização da metodologia e a uniformidade de resultados obtidos (BURRIS 
\& NAVRATIL, 1979). Desta forma, os efeitos são menos drásticos que os observados em testes com terra, mas a simplicidade de sua execução e a maior precisão dos resultados justificam o seu uso. $\mathrm{Na}$ atualidade é uma metodologia alternativa de maior simplicidade e com vantagens para a padronização.

Os mesmos autores, ainda citaram que o teste de frio não pode ser padronizado quando o solo é um dos componentes, e propõe o desenvolvimento de um teste de frio, incorporando apenas baixa temperatura e sem a adição de solo que seria um fator de variação dos resultados. $\mathrm{O}$ uso de substrato esterilizado foi similar aos testes com terra e a principal resposta das sementes foi em relação ao estresse da temperatura durante a embebição e não ao solo. Em contraste, a eliminação de patógenos nos estudos feitos por WOLTZ (1997), resultaram em porcentagens de germinação acima de 95\% para todos os lotes e em todos os níveis de umidade e temperatura testadas. Diferenças entre lotes, entre tratamentos de sementes ou influências de fatores ambientais (umidade de solo e temperatura) não puderam ser detectados quando os patógenos do solo foram eliminados, portanto, o uso de substrato esterilizado para uma padronização do teste de frio parece não ser praticável.

Grande variabilidade nos resultados do teste de frio foi encontrada por CROSIER (1957), sendo que a porcentagem de germinação para sementes de milho tratadas foi de $88 \%$ para rolo de papel, $83 \%$ para terra em caixa e $72 \%$ para o método com solo inundado. Para sementes não tratadas, a máxima germinação observada foi com o método de terra em caixa $(52 \%)$, seguido pelo rolo de papel $(42 \%)$ e solo inundado (10\%). Os fungos Gibberella zeae e Pythium foram as principais espécies responsáveis pela redução da germinação.

Ao comparar diferentes metodologias do teste de frio, observa-se que os métodos que oferecem condições mais estressantes são os melhores para separar lotes de sementes com diversos níveis de vigor. Quando as metodologias são comparadas dentro de um mesmo laboratório, a variabilidade do teste de frio é bastante reduzida, tornandoo viável para separar lotes com diferentes níveis de vigor. Porém, entre laboratórios a variabilidade é bem acentuada, dificultando a comparação e reprodutibilidade dos 
resultados. Há uma tendência para menores variações quando se utiliza os métodos sem terra (rolo de papel sem terra) ou os métodos que incorporem menores quantidades deste componente (método da bandeja), sendo que o último geralmente se correlaciona bem com a emergência em campo.

Conforme citado anteriormente, o teste de frio quando envolve o uso de solo, apresenta problemas com relação a padronização, devido a sua alta variabilidade tanto física quanto biológica, fato este que explica a obtenção de resultados desuniformes entre laboratórios (CICERO e VIERA, 1994). Nesse caso, a presença de microrganismos exerce grande influência nos resultados obtidos, devido à baixa temperatura e o excesso de água no solo favorecerem o desenvolvimento de alguns microrganismos patogênicos, como Phytium spp. e Giberella zeae. Apesar do exposto, a utilização do solo como substrato é um fator muito interessante, quando se considera que com o seu uso é possível avaliar a eficiência de tratamentos fungicidas.

CICERO et al. (1989), constataram que, quando sementes de milho são tratadas com fungicidas, os índices de germinação e emergência são significativamente superiores quando comparados com a testemunha sem tratamento. Tal fato se deve às sementes sofrerem menores danos provocados por fungos patogênicos atuantes nessas condiçães desfavoráveis à germinação da plântula .

O efeito do tratamento com Captan $囚$ foi claramente influenciado pela umidade do solo $\mathrm{e}$, as diferenças de vigor foram mais aparentes em solos com conteúdo de umidade entre $50 \%$ a $75 \%$ da capacidade de campo. Em substratos esterilizados, o tratamento fungicida, em sementes de milho, não influenciou os testes com sementes não tratadas, e, em solo ou substrato esterilizado, houve melhor correlação com a emergência em campo do que o teste com terra e sementes tratadas ou do que o teste de germinação padrão. Caso as características de solo sejam controladas, o teste de frio para sementes não tratadas será provavelmente um teste rápido e com alta reprodutibilidade para a avaliação de vigor e também para testar a eficiência de tratamento com fungicidas (BRUGGINK et al., 1991). 
FRATIN (1987), observou em sementes de milho, que o teste de frio revelou maior sensibilidade para definir a qualidade de lotes, em relação a outros métodos de vigor convencionalmente utilizados.

A eficiência do teste de frio foi comprovada experimentalmente por diversos pesquisadores, e foi sugerido seu uso na seleção de linhagens de milho antes do periodo de semeadura, devido a sua sensibilidade em prognosticar o desempenho das sementes em campo. Dessa forma, muitas empresas produtoras de sementes de milho utilizam esse teste nos programas internos de controle de qualidade (TEKRONY, 1983). Através do conhecimento das condições não favoráveis de campo, as empresas mantém um rígido padrão antes da comercialização. Elas usam o teste de frio, para predizer a emergência sob condições de frio e umidade (WAES, 1995). Esse teste tem sido utilizado com sucesso, também, para diferenciar níveis de vigor relacionados com a forma, peso, tamanho e tratamento de sementes (MARCOS FILHO et al. 1977; SILVA \& MARCOS FILHO, 1979). Foi também demonstrado por THRONEBERRY \& SMITH (1955), que os danos ocasionados às sementes durante o processo de secagem eram mais facilmente evidenciados com o teste de frio.

FRATIN (1987) concluiu que, dentre os testes utilizados para a avaliação da qualidade fisiológica de sementes de milho, o teste de frio com utilização de terra e o de envelhecimento acelerado podem ser considerados como os mais eficientes, visando a identificação do potencial de emergência das plântulas, do potencial de armazenamento das sementes e da separação dos lotes em diferentes níveis de vigor. Ainda, afirmou que o teste de frio sem a utilização de terra, apesar de proporcionar efeitos menos drásticos às sementes e resultados menos variáveis em relação ao frio com terra, permite identificar, principalmente, as diferenças acentuadas na qualidade fisiológica das sementes.

Tem se verificado boa correlação entre teste de frio e emergência em campo; entretanto, condições climáticas (entre anos e regiões) podem também influenciar na correlação entre os resultados do teste de frio e emergência em campo (WASSINK e HOEFMAN, 1992). 
O teste de frio tem sido usado, principalmente para sementes de milho, porém seu uso para outras espécies como soja, feijão, algodão e ervilha tem crescido significativamente, principalmente nos Estados Unidos da América e Europa (AOSA, 1983). No caso da soja, FERRISS e BAKER (1990) concluíram que o teste para avaliar a qualidade de semente de soja que melhor estima a emergência no campo, pode variar com as condições de solo, principalmente no que diz respeito à umidade, temperatura $\mathrm{e}$ microbiota.

Além dessas espécies, o teste pode ser utilizado para outras, embora em alguns casos possa ser necessária a adaptação da metodologia para atender as características de cada espécie (CICERO e VIEIRA, 1994). 


\section{MATERIAL E MÉTODOS}

A pesquisa foi conduzida no Laboratório de Análise de Sementes (LAS) e em área experimental do Departamento de Agricultura da Escola Superior de Agricultura "Luiz de Queiroz "(LAG/ESALQ), Universidade de São Paulo (USP), no municipio de Piracicaba - SP.

O experimento foi conduzido nos anos de 1997/1998, em duas épocas com intervalo de quatro meses. Foram utilizadas sementes de três cultivares de soja, FT-5, OCEPAR-13 e BR-16 e dois cultivares de feijão, Carioca Comum e IAC Carioca, provenientes de três lotes com diferentes qualidades fisiológicas para cada material. Essas sementes durante o período experimental foram armazenadas em condições de ambiente não controlado.

\subsection{Metodologias utilizadas para o teste de frio}

\subsubsection{Teste de frio com terra - semeadura em caixas plásticas}

Foram semeadas, em caixas plásticas com dimensões de $47 \mathrm{~cm} \mathrm{x} 30 \mathrm{~cm} \mathrm{x}$ $11 \mathrm{~cm}$, quatro repetições de 100 sementes para cada lote de cada cultivar em substrato constituído por $2 / 3$ de areia e $1 / 3$ de terra, provenientes de áreas cultivadas com feijão e soja, respectivamente. O substrato foi irrigado com água até atingir $60 \%$ da sua capacidade de retenção. As sementes permaneceram em condições conforme descritas a seguir:

$\mathrm{T}_{1}$ - teste de frio com terra, durante sete dias à $10^{\circ} \mathrm{C}$;

$\mathrm{T}_{2}$ - teste de frio com terra, durante sete dias à $15^{\circ} \mathrm{C}$;

$\mathrm{T}_{3}$ - teste de frio com terra, durante cinco dias à $10^{\circ} \mathrm{C}$;

$\mathrm{T}_{4}$ - teste de frio com terra, durante cinco dias à $15^{\circ} \mathrm{C}$;

$\mathrm{T}_{5}$ - teste de frio com terra, durante três dias à $10^{\circ} \mathrm{C}$;

$\mathrm{T}_{6}$ - teste de frio com terra, durante três dias à $15^{\circ} \mathrm{C}$. 
Após a permanência em câmara fria, as caixas foram retiradas e colocadas em condição de ambiente não controlado do LAS/LAG/ESALQ/USP, onde permaneceram por sete dias, quando foi procedida a contagem das plântulas emersas.

\subsubsection{Teste de frio em rolo de papel com terra}

Foram instaladas quatro repetições de 100 sementes para cada lote de cada cultivar em rolos de papel toalha Germitest, umedecidos com quantidade de água equivalente a 2,5 vezes o peso dos papéis.

As sementes foram distribuídas em duas folhas de papel e sobre as sementes foi colocada uma fina camada de terra, proveniente de área cultivada com feijão e outra com soja e, a seguir, cobertas com outra folha de papel. Esses rolos foram colocados em caixas plásticas, vedadas e, em seguida, mantidos nas condições descritas a seguir:

$\mathrm{T}_{7}$ - teste de frio, em rolo de papel com terra, durante sete dias à $10^{\circ} \mathrm{C}$;

$\mathrm{T}_{8}$ - teste de frio, em rolo de papel com terra, durante sete dias à $15^{\circ} \mathrm{C}$; $\mathrm{T}_{9}$ - teste de frio, em rolo de papel com terra, durante cinco dias à $10^{\circ} \mathrm{C}$; $\mathrm{T}_{10}$ - teste de frio, em rolo de papel com terra, durante cinco dias à $15^{\circ} \mathrm{C}$;

$\mathrm{T}_{11}$ - teste de frio, em rolo de papel com terra, durante três dias à $10^{\circ} \mathrm{C}$;

$\mathrm{T}_{12}$ - teste de frio, em rolo de papel com terra, durante três dias à $15^{\circ} \mathrm{C}$.

Decorridos os respectivos períodos, os rolos foram transferidos para germinador, a temperatura de $25^{\circ} \mathrm{C}$, por quatro dias, quando foram efetuadas as contagens de plântulas normais. Os resultados foram expressos em porcentagem. 


\subsubsection{Teste de frio em rolo de papel sem terra}

Os procedimentos foram semelhantes ao descrito no item anterior (3.1.2), com exceção da colocação de camada de terra sobre as sementes. As condições em que as sementes foram submetidas está descrita a seguir :

$\mathrm{T}_{13}$ - teste de frio, em rolo de papel sem terra, durante sete dias à $10^{\circ} \mathrm{C}$;

$\mathrm{T}_{14}$ - teste de frio, em rolo de papel sem terra, durante sete dias à $15^{\circ} \mathrm{C}$;

$\mathrm{T}_{15}$ - teste de frio, em rolo de papel sem terra, durante cinco dias à $10^{\circ} \mathrm{C}$;

$\mathrm{T}_{16}$ - teste de frio, em rolo de papel sem terra, durante cinco dias à $15^{\circ} \mathrm{C}$;

$\mathrm{T}_{17}$ - teste de frio, em rolo de papel sem terra, durante três dias à $10^{\circ} \mathrm{C}$;

$\mathrm{T}_{18}$ - teste de frio, em rolo de papel sem terra, durante três dias à $15^{\circ} \mathrm{C}$.

\subsection{Outras determinações utilizadas para avaliar a qualidade dos lotes de sementes}

\subsubsection{Determinação do grau de umidade}

Foi efetuado pelo método da estufa a $105^{\circ} \mathrm{C} \pm 3^{\circ} \mathrm{C}$ durante 24 horas, conforme as Regras para Análise de Sementes (BRASIL, M. A., 1992).

\subsubsection{Teste padrão de germinação}

Foi conduzido com quatro repetições de 50 sementes para cada lote de cada cultivar de cada espécie, em rolos de papel toalha, em germinador regulado à $25^{\circ} \mathrm{C}$. A quantidade de água adicionada foi equivalente a 2,5 vezes o peso do substrato seco, visando umedecimento adequado, e consequentemente uniformização do teste. As contagens, no $4^{\circ}$ e $7^{\circ}$ dias após a semeadura, seguiram os critérios estabelecidos nas Regras para Análise de Sementes ( BRASIL, M. A., 1992 ), com resultados expressos em média de plântulas normais. 


\subsubsection{Primeira contagem de germinação}

Conduzido em conjunto com o teste de germinação, computando-se as porcentagens de plântulas normais na data prevista ( $4^{\circ}$ dias após a semeadura) para primeira contagem no teste de germinação.

\subsubsection{Envelhecimento acelerado}

O procedimento adotado foi o proposto pela AOSA (1983), pelo método do gerbox, em incubadora regulada a $41^{\circ} \mathrm{C}$. Para as sementes de feijão, o período em incubadora foi de 72 horas e para a soja 48 horas. Decorridos esses períodos, quatro repetições de 50 sementes de cada lote, de cada cultivar, em cada espécie, foram colocadas em rolos de papel Germitest e postas a germinar de maneira semelhante a descrita para a germinação. A interpretação do teste foi realizada no $4^{\circ}$ dia após a semeadura. Os resultados foram expressos em porcentagens médias de plântulas normais.

\subsubsection{Condutividade elétrica}

Realizado com quatro repetições de 50 sementes para cada lote de cada cultivar de cada espécie. As sementes foram pesadas com precisão de duas casas decimais e, em seguida, colocadas em copos plásticos contendo $75 \mathrm{ml}$ de água destilada. As sementes foram embebidas por 24 horas, em germinador a $25^{\circ} \mathrm{C}$. Após esse periodo, cada copo foi agitado ligeiramente, e a condutividade elétrica avaliada por um condutivímetro. A avaliação foi realizada pela leitura da condutividade elétrica da solução, com resultados expressos em $\mu \mathrm{mhos} / \mathrm{cm} / \mathrm{g}$. 


\subsubsection{Emergência de plântulas em campo}

O teste foi conduzido em área experimental do Departamento de Agricultura, com quatro repetições de 100 sementes para cada lote de cada cultivar, para cada espécie. O solo foi mantido com umidade suficiente através de irrigações para promover a emergência das plântulas. A semeadura foi realizada em duas épocas, sendo a primeira em 05/12/97 e a segunda em 15/04/98. A profundidade de semeadura foi de $3-4 \mathrm{~cm}$. A avaliação das plântulas emergidas foi realizada aos 15 dias após a semeadura.

\subsubsection{Sanidade das sementes}

Conduzido pelo método do papel de filtro sem congelamento, conforme NEEGARD (1977), com a utilização de 200 sementes para cada lote de cada cultivar, para cada espécie.

\subsubsection{Análise da terra utilizada nos testes de frio}

Com a finalidade de detectar os patógenos presentes na terra utilizada nos testes de frio, foi conduzida análise pelo método isca, utilizando-se pecíolos de plântulas de feijão e de soja. Os resultados foram expressos em porcentagem de pecíolos infectados SNEH et al. (1966).

\subsection{Delineamento estatístico}

O delineamento experimental foi o inteiramente casualizado com 18 tratamentos comespondentes às metodologias utilizadas no teste de frio. Os dados porcentuais sofreram transformação em Arco Seno $(\% / 100)^{0,5}$. 
A análise da variância para as metodologias do teste de frio foi realizada separadamente para cada lote em cada cultivar de cada espécie.

Os dados obtidos nos testes de primeira contagem, envelhecimento acelerado, condutividade elétrica e emergência em campo foram submetidos à análise de correlação simples, com sua significância testada através do teste $t$, visando. selecionar a melhor combinação de temperatura, periodo de exposição e substrato que melhor evidenciasse os níveis de qualidade e apresentasse melhor correlação entre as diferentes metodologias do teste de frio com os demais testes de vigor.

$\mathrm{Na}$ execução das análises estatísticas foi utilizado o "Sistema de Análise Estatística para Microcomputadores - SANEST". 


\section{RESULTADOS E DISCUSSÃO}

\subsection{Sementes de feijão}

A análise da variância para sementes de feijão, cultivar Carioca Comum mostrou haver diferenças significativas entre as diferentes metodologias para o teste de frio para os lotes 1 e 2. Já para o lote 3 , o teste revelou não haver diferenças significativas.

Na Tabela 1, observa-se, pelo teste de Tukey, que para as sementes de feijão Carioca Comum do lote 1 na primeira época, as metodologias que proporcionaram maior redução de emergência, caracterizando-se como metodologias mais drásticas, foram os tratamentos que envolveram rolo de papel com terra, com sete dias de exposição à $15^{\circ} \mathrm{C}$, seguido do tratamento caixa, com sete dias de exposição à $10^{\circ} \mathrm{C}$ e por fim o tratamento de rolo de papel com terra, com cinco dias de exposição à $15^{\circ} \mathrm{C}$. Ainda em relação ao lote 1 , as metodologias menos drásticas foram observadas em todos tratamentos que envolveram caixa, com exceção do tratamento com sete dias à $10^{\circ} \mathrm{C}$ citado anteriormente, rolo de papel com terra à $10^{\circ} \mathrm{C}$ quando as sementes foram submetidas a períodos de sete e cinco dias de exposição e todas as metodologias que envolveram rolo de papel sem terra.

Para o lote 2, ainda do cultivar Carioca Comum, as metodologias que proporcionaram maior redução de emergência de plântulas foram os tratamentos que envolveram rolo de papel com terra com sete e cinco dias de exposição à $15^{\circ} \mathrm{C}$.

As sementes quando submetidas a metodologia de rolo de papel com terra à $15^{\circ} \mathrm{C}$, por períodos de cinco e sete dias, apresentaram elevada incidência de fungos. Verificou-se que a medida que o período de exposição das sementes sob essas condições aumentava, aumentava significativamente a incidencia de fungos, em função da 
ocorrência de condições favoráveis ao seu desenvolvimento. Durante três dias de exposição à $15^{\circ} \mathrm{C}$, não foi detectado a presença de fungos, devido ao tempo insuficiente para o seu desenvolvimento. Porém, quando expostas a cinco e, principalmente, a sete dias, houve diferenças significativas em relação a outras metodologias estudadas. A presença dos fungos Rhizoctonia e Fusarium foi verificada tanto na análise de sanidade de sementes, como na análise de terra realizada com o intuito de deteç̧ão de patógenos (Tabelas 2 e 3). Segundo CARDOSO (1994), estes fungos sobrevivem saprofiticamente no solo, geralmente nas camadas superficiais $( \pm 10 \mathrm{~cm})$ devido a sua forte dependência de oxigênio e são favorecidos por umidades próximas à saturação. Já o mesmo teste de rolo de papel com terra, porém com temperatura de $10^{\circ} \mathrm{C}$ ao invés de $15^{\circ} \mathrm{C}$, não propiciou condições tão favoráveis ao desenvolvimento dos fungos Rhizoctonia e Fusarium, uma vez que estes não chegaram a interferir nos resultados do teste. Há concordância dos resultados observados no presente trabalho com as afirmações de WONG et al. (1984) e NIJENSTEIN (1995) de que a umidade e a temperatura do solo afetam a severidade das doenças causadas por Rhizoctonia e Fusarium.

Segundo STOCKWELL \& HANCHEY (1984), citado por CARDOSO (1994), o feijoeiro é suscetivel aos patógenos Rhizoctonia e Fusarium, a partir da germinação, reduzindo esta suscetibilidade à medida que a planta se desenvolve, devido a lignificação dos tecidos e engrossamento da parede celular pela deposição de pectatos de cálcio. Assim, nessa fase, ou seja, na germinação e emergência, qualquer condição favorável ao desenvolvimento dos fungos é extremamente prejudicial à plântula de feijão, pois esta se encontra em sua fase mais suscetível com relação aos patógenos. 
Ainda, no lote 2 , os tratamentos onde a emergência foi maior, envolveu os tratamentos caixa com sete dias de exposição a $10^{\circ} \mathrm{C}$ e cinco dias de exposição a $15^{\circ} \mathrm{C}$, apesar de não terem diferido estatisticamente de outros tratamentos.

Para o lote 3 , não foi verificado diferenças significativas entre as metodologias, ou seja, apesar de alguns tratamentos apresentarem emergências mais baixas, estes valores não foram significativamente diferentes dos demais.

Tabela 1 - Médias ${ }^{1}(\%)$ e coeficientes de variação (\%) referentes às diferentes metodologias do teste de frio realizados nos lotes de sementes de feijão, cultivar Carioca Comum, observados na $1^{2}$ época.

\begin{tabular}{llll}
\hline Tratamentos & Lote 1 & Lote 2 & Lote 3 \\
\hline $\mathrm{Cx} 7 \mathrm{D} 10^{\circ} \mathrm{C}$ & $55,6 \mathrm{~cd}$ & $97,2 \mathrm{a}$ & $82,6 \mathrm{a}$ \\
$\mathrm{Cx} 7 \mathrm{D} 15^{\circ} \mathrm{C}$ & $96,7 \mathrm{a}$ & $79,6 \mathrm{abcd}$ & $82,7 \mathrm{a}$ \\
$\mathrm{Cx}$ 5D $10^{\circ} \mathrm{C}$ & $84,3 \mathrm{abc}$ & $96,0 \mathrm{ab}$ & $85,7 \mathrm{a}$ \\
$\mathrm{Cx}$ 5D $15^{\circ} \mathrm{C}$ & $95,8 \mathrm{a}$ & $96,6 \mathrm{a}$ & $90,1 \mathrm{a}$ \\
$\mathrm{Cx}$ 3D $10^{\circ} \mathrm{C}$ & $87,9 \mathrm{a}$ & $96,3 \mathrm{ab}$ & $86,7 \mathrm{a}$ \\
Cx 3D $15^{\circ} \mathrm{C}$ & $94,8 \mathrm{a}$ & $95,3 \mathrm{ab}$ & $90,6 \mathrm{a}$ \\
RPCT 7D $10^{\circ} \mathrm{C}$ & $89,6 \mathrm{a}$ & $89,2 \mathrm{abcd}$ & $75,2 \mathrm{a}$ \\
RPCT 7D $15^{\circ} \mathrm{C}$ & $44,6 \mathrm{~d}$ & $71,8 \mathrm{~cd}$ & $74,5 \mathrm{a}$ \\
RPCT 5D $10^{\circ} \mathrm{C}$ & $89,6 \mathrm{a}$ & $89,9 \mathrm{abcd}$ & $81,6 \mathrm{a}$ \\
RPCT 5D $15^{\circ} \mathrm{C}$ & $59,5 \mathrm{bcd}$ & $67,1 \mathrm{~d}$ & $81,0 \mathrm{a}$ \\
RPCT 3D $10^{\circ} \mathrm{C}$ & $92,7 \mathrm{a}$ & $92,5 \mathrm{abc}$ & $78,5 \mathrm{a}$ \\
RPCT 3D $15^{\circ} \mathrm{C}$ & $89,2 \mathrm{a}$ & $86,1 \mathrm{abcd}$ & $81,7 \mathrm{a}$ \\
RPST 7D $10^{\circ} \mathrm{C}$ & $84,2 \mathrm{abc}$ & $87,5 \mathrm{abcd}$ & $73,8 \mathrm{a}$ \\
RPST 7D $15^{\circ} \mathrm{C}$ & $90,2 \mathrm{a}$ & $75,6 \mathrm{bcd}$ & $85,2 \mathrm{a}$ \\
RPST 5D $10^{\circ} \mathrm{C}$ & $90,7 \mathrm{a}$ & $94,4 \mathrm{abc}$ & $79,0 \mathrm{a}$ \\
RPST 5D $15^{\circ} \mathrm{C}$ & $90,6 \mathrm{a}$ & $81,2 \mathrm{abcd}$ & $80,8 \mathrm{a}$ \\
RPST 3D $10^{\circ} \mathrm{C}$ & $87,7 \mathrm{ab}$ & $90,4 \mathrm{abcd}$ & $74,6 \mathrm{a}$ \\
RPST 3D $15^{\circ} \mathrm{C}$ & $91,8 \mathrm{a}$ & $86,7 \mathrm{abcd}$ & $76,8 \mathrm{a}$ \\
\hline CV & 10,8 & 10,1 & 8,7 \\
\hline
\end{tabular}

${ }^{T}$ Médias seguidas por letras distintas na coluna diferem entre si pelo teste de Tukey, ao nivel de $5 \%$ de significância.

${ }^{2} \mathrm{C} x=$ Caixa; $\mathrm{RPCT}=$ Rolo de papel com terra; $\mathrm{RPST}=$ rolo de papel sem terra $\mathrm{e}=$ dias de exposição.

A análise da variância para a segunda época revelou, pelo teste de $F$, que não houve diferença significativa entre as diferentes metodologias para os três lotes estudados. Na Tabela 4 encontram-se os valores médios de emergência para os três lotes do cultivar Carioca Comum. 

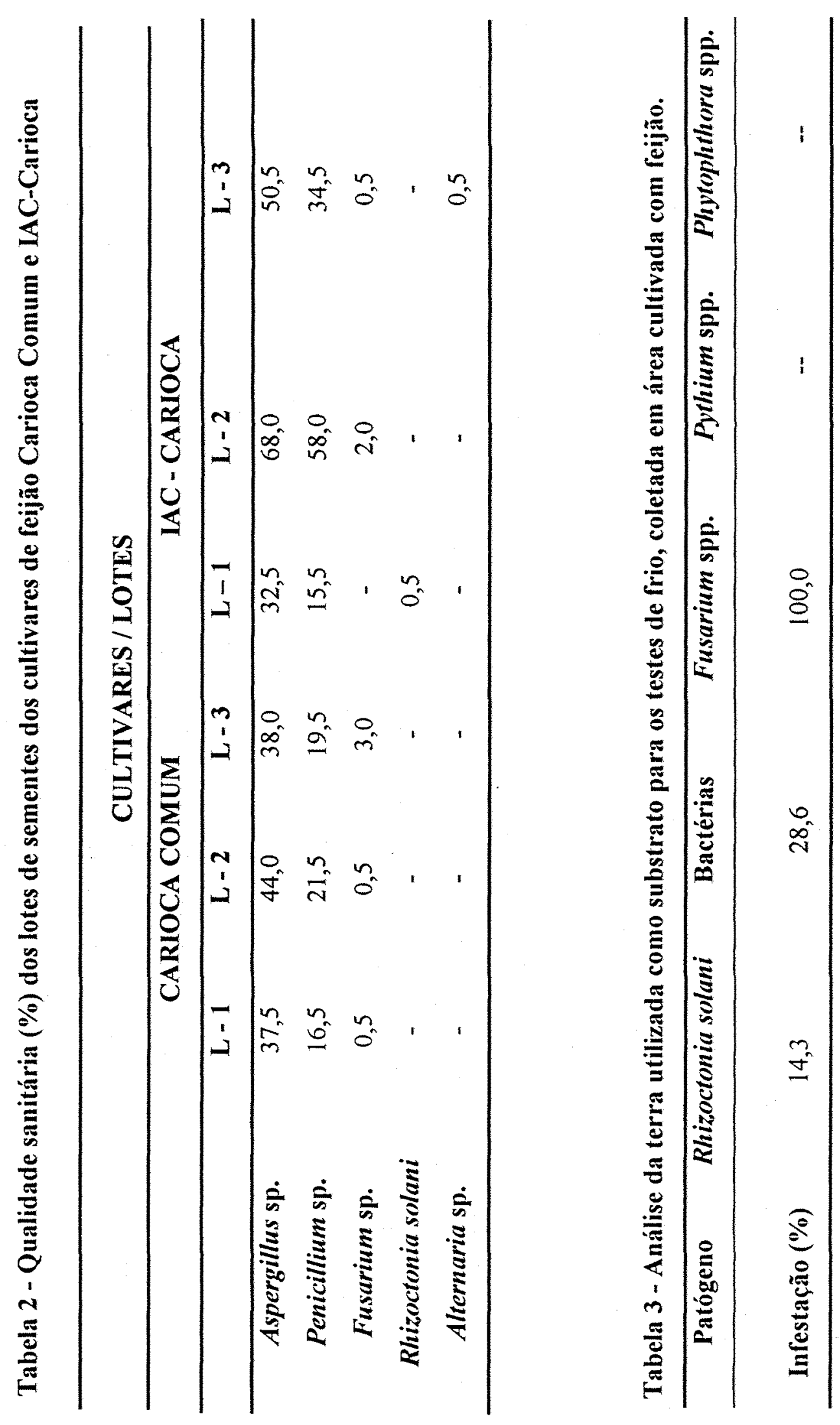
Tabela 4 - Médias ${ }^{1}(\%)$ e coeficientes de variação $(\%)$ referentes às diferentes metodologias do teste de frio realizados nos lotes de sementes de feijão, cultivar Carioca Comum, observados na $2^{\mathrm{a}}$ época.

\begin{tabular}{llll}
\hline Tratamentos & Lote 1 & Lote 2 & Lote 3 \\
\hline Cx 7D $10^{\circ} \mathrm{C}$ & $91,0 \mathrm{a}$ & $83,6 \mathrm{a}$ & $86,4 \mathrm{a}$ \\
$\mathrm{Cx} 7 \mathrm{D} 15^{\circ} \mathrm{C}$ & $94,4 \mathrm{a}$ & $93,1 \mathrm{a}$ & $86,8 \mathrm{a}$ \\
$\mathrm{Cx} \mathrm{5D} 10^{\circ} \mathrm{C}$ & $88,7 \mathrm{a}$ & $89,3 \mathrm{a}$ & $79,9 \mathrm{a}$ \\
Cx 5D $15^{\circ} \mathrm{C}$ & $95,7 \mathrm{a}$ & $93,7 \mathrm{a}$ & $79,9 \mathrm{a}$ \\
Cx 3D $10^{\circ} \mathrm{C}$ & $94,6 \mathrm{a}$ & $87,5 \mathrm{a}$ & $84,2 \mathrm{a}$ \\
Cx 3D $15^{\circ} \mathrm{C}$ & $91,2 \mathrm{a}$ & $89,9 \mathrm{a}$ & $84,8 \mathrm{a}$ \\
RPCT 7D $10^{\circ} \mathrm{C}$ & $91,6 \mathrm{a}$ & $88,1 \mathrm{a}$ & $83,1 \mathrm{a}$ \\
RPCT 7D $15^{\circ} \mathrm{C}$ & $88,3 \mathrm{a}$ & $89,4 \mathrm{a}$ & $78,5 \mathrm{a}$ \\
RPCT 5D $10^{\circ} \mathrm{C}$ & $95,7 \mathrm{a}$ & $91,6 \mathrm{a}$ & $88,1 \mathrm{a}$ \\
RPCT 5D $15^{\circ} \mathrm{C}$ & $86,0 \mathrm{a}$ & $93,2 \mathrm{a}$ & $75,7 \mathrm{a}$ \\
RPCT 3D $10^{\circ} \mathrm{C}$ & $94,7 \mathrm{a}$ & $95,2 \mathrm{a}$ & $82,1 \mathrm{a}$ \\
RPCT 3D $15^{\circ} \mathrm{C}$ & $89,3 \mathrm{a}$ & $95,1 \mathrm{a}$ & $87,6 \mathrm{a}$ \\
RPST 7D $10^{\circ} \mathrm{C}$ & $93,7 \mathrm{a}$ & $91,9 \mathrm{a}$ & $87,1 \mathrm{a}$ \\
RPST 7D $15^{\circ} \mathrm{C}$ & $94,6 \mathrm{a}$ & $91,3 \mathrm{a}$ & $89,0 \mathrm{a}$ \\
RPST 5D $10^{\circ} \mathrm{C}$ & $90,0 \mathrm{a}$ & $93,7 \mathrm{a}$ & $88,6 \mathrm{a}$ \\
RPST 5D $15^{\circ} \mathrm{C}$ & $96,1 \mathrm{a}$ & $95,1 \mathrm{a}$ & $85,2 \mathrm{a}$ \\
RPST 3D $10^{\circ} \mathrm{C}$ & $95,8 \mathrm{a}$ & $90,6 \mathrm{a}$ & $86,2 \mathrm{a}$ \\
RPST 3D $15^{\circ} \mathrm{C}$ & $94,4 \mathrm{a}$ & $94,1 \mathrm{a}$ & $86,1 \mathrm{a}$ \\
\hline C.V & 6,0 & 7,3 & 6,0
\end{tabular}

'Médias seguidas por letras distintas na coluna diferem entre si pelo teste de Tukey, ao nível de $5 \%$ de significância.

${ }^{2} \mathrm{Cx}=$ Caixa; $\mathrm{RPCT}=$ Rolo de papel com terra; RPST $=$ rolo de papel sem terra e $\mathrm{D}=$ dias de exposição.

Quando a análise foi realizada para o cultivar IAC Carioca na primeira época, o teste de $\mathrm{F}$ mostrou haver diferença significativa para os três lotes estudados. Na Tabela 5, o resultado do teste de Tukey para o lote 1 mostrou que o tratamento que proporcionou maior redução de emergência de plântulas foi o rolo de papel com terra no periodo de exposição de sete dias à $15^{\circ} \mathrm{C}$, diferindo significativamente dos demais tratamentos. Neste mesmo lote, o tratamento que menos reduziu a emergência foi o tratamento caixa com três dias de exposição à $15^{\circ} \mathrm{C}$, apesar de não ter diferido significativamente da maioria dos demais tratamentos. Para o lote 2 , os tratamentos que proporcionaram maior redução de emergência foram o rolo de papel com terra, com sete dias de exposição à $15^{\circ} \mathrm{C}$ e o rolo de papel com terra com cinco dias de exposição à $15^{\circ} \mathrm{C}$. O tratamento que se revelou menos drástico às sementes foi o rolo de papel com terra com três dias de exposição à $10^{\circ} \mathrm{C}$. Para o lote 3 , novamente foi observado que $o$ 
rolo de papel com terra com sete dias de exposição a $15^{\circ} \mathrm{C}$ se mostrou mais drástico em relação à maioria dos demais tratamentos, ao passo que o tratamento que menos afetou a emergência foi caixa com cinco dias a $15^{\circ} \mathrm{C}$

Tabela 5 - Médias ${ }^{1}(\%)$ e coeficientes de variação (\%) referentes às diferentes metodologias do teste de frio realizados nos lotes de sementes de feijão, cultivar IAC Carioca, observados na $1^{\text {a época. }}$

\begin{tabular}{|c|c|c|c|}
\hline Tratamentos $^{2}$ & Lote 1 & Lote 2 & Lote 3 \\
\hline $\mathrm{C} \times 7 \mathrm{D} 10^{\circ} \mathrm{C}$ & $93,6 \mathrm{abc}$ & 84,4 abc & $95,4 \mathrm{abc}$ \\
\hline $\mathrm{Cx} 7 \mathrm{D} 15^{\circ} \mathrm{C}$ & $86,5 \mathrm{abc}$ & $87,1 \mathrm{ab}$ & 83,9 abc \\
\hline $\mathrm{Cx} 5 \mathrm{D} 10^{\circ} \mathrm{C}$ & $97,4 a b c$ & $81,0 \mathrm{abc}$ & $85,9 a b c$ \\
\hline $\mathrm{Cx} 5 \mathrm{D} 15^{\circ} \mathrm{C}$ & $98,7 \mathrm{ab}$ & $91,9 \mathrm{ab}$ & 99,3 a \\
\hline $\mathrm{Cx} 3 \mathrm{D} 10^{\circ} \mathrm{C}$ & $95,9 \mathrm{abc}$ & $90,0 \mathrm{ab}$ & $93,7 \mathrm{abc}$ \\
\hline $\mathrm{Cx} 3 \mathrm{D} 15^{\circ} \mathrm{C}$ & 99,4 a & $88,6 \mathrm{ab}$ & $96,7 \mathrm{ab}$ \\
\hline RPCT $7 D 10^{\circ} \mathrm{C}$ & $90,5 \mathrm{abc}$ & $81,4 \mathrm{abc}$ & $69,8 \quad \mathrm{~cd}$ \\
\hline RPCT $7 D 15^{\circ} \mathrm{C}$ & 37,7 & 64,1 & 35,4 \\
\hline RPCT 5D $10^{\circ} \mathrm{C}$ & $80,2 \quad c$ & $91,0 \mathrm{ab}$ & $90,1 \mathrm{abc}$ \\
\hline $\mathrm{RPCT} 5 \mathrm{D} 15^{\circ} \mathrm{C}$ & $83,7 \quad b c$ & 63,7 & 79,3 bc \\
\hline RPCT 3D $10^{\circ} \mathrm{C}$ & $88,0 a b c$ & $92,4 \mathrm{a}$ & $89,0 \mathrm{abc}$ \\
\hline $\mathrm{RPCT} 3 \mathrm{D} 15^{\circ} \mathrm{C}$ & $96,1 \mathrm{abc}$ & $83,2 \mathrm{abc}$ & $86,9 \mathrm{abc}$ \\
\hline RPST $7 D 10^{\circ} \mathrm{C}$ & $95,7 \mathrm{abc}$ & $73,1 \quad b c$ & $96,7 \mathrm{ab}$ \\
\hline RPST $7 \mathrm{D} 15^{\circ} \mathrm{C}$ & $92,9 \mathrm{abc}$ & $88,8 \mathrm{ab}$ & $91,6 \mathrm{abc}$ \\
\hline RPST $5 \mathrm{D} 10^{\circ} \mathrm{C}$ & $92,4 \mathrm{abc}$ & $91,9 a b$ & $90,5 \mathrm{abc}$ \\
\hline RPST $5 \mathrm{D} 15^{\circ} \mathrm{C}$ & $90,7 \mathrm{abc}$ & $79,6 \mathrm{abc}$ & 88,7 abc \\
\hline RPST $3 D 10^{\circ} \mathrm{C}$ & $93,0 \mathrm{abc}$ & $91,0 \mathrm{ab}$ & $95,7 \mathrm{abc}$ \\
\hline RPST $3 \mathrm{D} 15^{\circ} \mathrm{C}$ & $97,7 \mathrm{abc}$ & 84,9 abc & $89,3 \mathrm{abc}$ \\
\hline C.V. & 9,4 & 8,6 & 12,2 \\
\hline
\end{tabular}

${ }^{T}$ Médias seguidas por letras distintas na coluna diferem entre si pelo teste de Tukey, ao nível de $5 \%$ de significância.

${ }^{2} \mathrm{Cx}=$ Caixa; $\mathrm{RPCT}=$ Rolo de papel com terra; $\mathrm{RPST}=$ rolo de papel sem terra e $\mathrm{D}=$ dias de exposição.

$\mathrm{Na}$ análise realizada na segunda época para a cultivar IAC Carioca, observou-se diferença significativa nos três lotes estudados. Na Tabela 6 , o resultado do teste de Tukey mostra que para o lote 1, o tratamento que proporcionou maior redução de emergência de plântulas foi o tratamento caixa com cinco dias de exposição a $10^{\circ} \mathrm{C} \mathrm{e}$ o que menos reduziu a emergência foi o rolo de papel sem terra com cinco dias de exposição à $15^{\circ} \mathrm{C}$. Para o lote 2, verificou-se que o tratamento rolo de papel com terra com sete dias de exposição a $15^{\circ} \mathrm{C}$ foi, como nos outros cultivares e épocas, o mais drástico entre as demais metodologias, apesar de não ter diferido significativamente de 
outros tratamentos. Ainda, com relação ao lote 2 , a maior emergência foi encontrada no tratamento rolo de papel sem terra com três dias de exposição à $15^{\circ} \mathrm{C}$. Os resultados obtidos para o lote 3 revelaram a mesma tendência dos demais em relação ao tratamento mais drástico, sendo que neste caso, os tratamentos que menos reduziram a emergência foram caixa com três dias à $10^{\circ} \mathrm{C}$ e rolo de papel sem terra com cinco dias à $15^{\circ} \mathrm{C}$.

Tabela 6 - Médias ${ }^{1}(\%)$ e coeficientes de variação $(\%)$ referentes às diferentes metodologias do teste de frio realizados nos lotes de sementes de feijão, cultivar IAC Carioca, observados na $2^{\mathrm{a}}$ época.

\begin{tabular}{|c|c|c|c|}
\hline Tratamentos ${ }^{2}$ & Lote 1 & Lote 2 & Lote 3 \\
\hline $\mathrm{Cx} 7 \mathrm{D} 10^{\circ} \mathrm{C}$ & 87,9 bcd & 72,8 & $91,5 \mathrm{abcd}$ \\
\hline $\mathrm{Cx} 7 \mathrm{D} 15^{\circ} \mathrm{C}$ & 90,7 abcd & cdef & 90,1 abcd \\
\hline $\mathrm{C} \times 5 \mathrm{D} 10^{\circ} \mathrm{C}$ & 63,3 & 68,5 & $78,6 \quad d$ \\
\hline $\mathrm{Cx}$ 5D $15^{\circ} \mathrm{C}$ & $96,0 \mathrm{ab}$ & 79,7 bcdef & $93,8 \mathrm{abcd}$ \\
\hline $\mathrm{Cx} 3 \mathrm{D} 10^{\circ} \mathrm{C}$ & $94,6 a b c$ & 80,2 abcdef & $97,3 \mathrm{a}$ \\
\hline $\mathrm{Cx} 3 \mathrm{D} 15^{\circ} \mathrm{C}$ & $93,1 a b c$ & 82,2 abcdef & $91,8 \mathrm{abcd}$ \\
\hline RPCT $7 D 10^{\circ} \mathrm{C}$ & 86,3 bcd & 71,1 & $88,7 \mathrm{abcd}$ \\
\hline RPCT 7D $15^{\circ} \mathrm{C}$ & 71,2 & 65,7 & 78,2 \\
\hline RPCT $5 \mathrm{D} 10^{\circ} \mathrm{C}$ & 86,2 bcde & 85,2 abcde & $83,5 \mathrm{bcd}$ \\
\hline RPCT $5 \mathrm{D} 15^{\circ} \mathrm{C}$ & 77,6 cde & 70,6 & $80,9 \quad \mathrm{~cd}$ \\
\hline RPCT $3 \mathrm{D} 10^{\circ} \mathrm{C}$ & 90,0 abcd & $91,2 \mathrm{ab}$ & 91,5 abcd \\
\hline RPCT $3 D 15^{\circ} \mathrm{C}$ & 87,5 bcd & $90,7 \mathrm{ab}$ & $93,7 \mathrm{abcd}$ \\
\hline RPST 7D $10^{\circ} \mathrm{C}$ & $91,3 \mathrm{abcd}$ & $92,4 \mathrm{ab}$ & $95,0 \mathrm{abc}$ \\
\hline RPST 7D $15^{\circ} \mathrm{C}$ & $96,8 \mathrm{ab}$ & $90,0 \mathrm{abc}$ & $96,8 \mathrm{ab}$ \\
\hline RPST 5D $10^{\circ} \mathrm{C}$ & $95,2 \mathrm{ab}$ & $92,1 \mathrm{ab}$ & 91,9 abcd \\
\hline RPST 5D $15^{\circ} \mathrm{C}$ & $99,5 \mathrm{a}$ & 89,1 abcd & 98,2 a \\
\hline RPST 3D $10^{\circ} \mathrm{C}$ & $96,7 \mathrm{ab}$ & $92,3 \mathrm{ab}$ & $95,3 \mathrm{abc}$ \\
\hline RPST 3D $15^{\circ} \mathrm{C}$ & $96,7 \mathrm{ab}$ & $93,8 \mathrm{a}$ & $95,7 \mathrm{abc}$ \\
\hline C.V. & 8,3 & 7,2 & 7,4 \\
\hline
\end{tabular}

Médias seguidas por letras distintas na coluna diferem entre si pelo teste de Tukey, ao nivel de $5 \%$ de significância.

${ }^{2} \mathrm{CX}=$ Caixa; $\mathrm{RPCT}=$ Rolo de papel com terra; $\mathrm{RPST}=$ rolo de papel sem terra e $\mathrm{D}=$ =dias de exposição.

De maneira geral, pode-se verificar que as sementes quando submetidas à periodos maiores de exposição à baixas temperaturas sofrem maior estresse que quando submetidas a períodos menores, provocando menor porcentagem de emergência de plântulas. Segundo WASSINK e HOEFMAN (1992), isso se deve ao fato de que em periodos de frio mais prolongados, ocorre uma maior exsudação de açúcares da semente, essenciais ao desenvolvimento. 
As metodologias que envolveram terra (rolo de papel com terra e caixa) foram mais drásticas em comparação com as que não envolveram (rolo de papel sem terra), concordando com CAMPOS (1998), que afirmou que isto se deve provavelmente a atividade de microrganismos no solo que é um fator crítico no teste de frio.

Em relação ao tratamento mais drástico, os diferentes cultivares, nas diferentes épocas se mostraram, de maneira geral, semelhantes; entretanto é importante a utilização de metodologias do teste de frio para sementes de feijão, que mais se aproxime dos resultados obtidos por outros de testes de vigor. Para que se possa obter esta informação, uma das maneiras é correlacionar o resultado de cada metodologia do teste de frio com os resultados de outros testes de vigor como, primeira contagem de germinação, envelhecimento acelerado, condutividade elétrica e emergência em campo (Tabelas 7 e 8 ) dos diferentes lotes e cultivares, nas diferentes épocas.

Tabela 7 - Grau de umidade (GU), germinação (G), primeira contagem de germinação (PCG), envelhecimento acelerado (EA), condutividade elétrica (CE) e emergência em campo (EC) dos lotes de sementes de feijão, cultivares Carioca Comum (CC) e IAC Carioca (IACC), observados na $1^{\text {a }}$ época.

\begin{tabular}{lcccccc}
\hline Cultivar/Lote & $\begin{array}{c}\text { GU } \\
(\mathbf{\% )}\end{array}$ & $\begin{array}{c}\text { G } \\
(\boldsymbol{\%})\end{array}$ & $\begin{array}{c}\text { PCG } \\
\mathbf{( \% )}\end{array}$ & $\begin{array}{c}\text { EA } \\
\mathbf{( \% )}\end{array}$ & $\begin{array}{c}\text { CE } \\
(\boldsymbol{\mu} \text { mhos/cm/g) }\end{array}$ & $\begin{array}{c}\text { EC } \\
(\boldsymbol{\%})\end{array}$ \\
\hline CC-L1 & 12,3 & 94 & 87 & 94 & 61 & 90 \\
CC-L2 & 12,8 & 96 & 89 & 80 & 57 & 94 \\
CC-L3 & 11,9 & 87 & 77 & 92 & 55 & 87 \\
\hline IACC-L1 & 12,5 & 99 & 93 & 92 & 69 & 87 \\
IACC- L2 & 12,0 & 94 & 87 & 92 & 70 & 90 \\
IACC-L3 & 12,7 & 97 & 86 & 77 & 77 & 90 \\
\hline
\end{tabular}


Tabela 8 - Grau de umidade (GU), germinação (G), primeira contagem de germinação (PCG), envelhecimento acelerado (EA), condutividade elétrica (CE) e emergência em campo (EC) dos lotes de sementes de feijão, cultivares Carioca Comum (CC) e IAC Carioca (IACC), observados na $2^{a}$ época.

\begin{tabular}{lcccccc}
\hline Cultivar/Lote & $\begin{array}{c}\text { GU } \\
(\boldsymbol{\%})\end{array}$ & $\begin{array}{c}\text { G } \\
(\boldsymbol{\%})\end{array}$ & $\begin{array}{c}\text { PCG } \\
(\boldsymbol{\%})\end{array}$ & $\begin{array}{c}\text { EA } \\
(\boldsymbol{\%})\end{array}$ & $\begin{array}{c}\text { CE } \\
(\boldsymbol{\mu m h o s} / \mathbf{c m} / \mathbf{g})\end{array}$ & $\begin{array}{c}\text { EC } \\
(\boldsymbol{\%})\end{array}$ \\
\hline CC-L1 & 13,5 & 97 & 94 & 87 & 71 & 97 \\
CC-L2 & 13,0 & 98 & 92 & 88 & 75 & 97 \\
CC-L3 & 13,4 & 93 & 88 & 87 & 75 & 89 \\
\hline LACC-L1 & 13,4 & 99 & 96 & 90 & 65 & 95 \\
LACC-L2 & 13,2 & 95 & 85 & 70 & 63 & 94 \\
LACC-L3 & 13,3 & 99 & 93 & 88 & 54 & 99 \\
\hline
\end{tabular}

Assim, verificou-se que os tratamentos rolo de papel sem terra, com três dias de exposição, nas temperaturas de $10^{\circ} \mathrm{C}$ e $15^{\circ} \mathrm{C}$, apresentaram valores de correlação de 0,80 e 0,84 , respectivamente, em relação ao teste de primeira contagem de germinação (Tabela 9).

Outros resultados interessantes com a primeira contagem ocorreram com os tratamentos rolos de papel sem terra com cinco dias de exposição nas temperaturas de $10^{\circ} \mathrm{C}$ e $15^{\circ} \mathrm{C}$ e com o tratamento rolo de papel com terra com sete dias de exposição à $10^{\circ} \mathrm{C}$, que apresentaram correlações entre 0,70 e 0,77 . Correlações em torno de 0,60 ocorreram com os tratamentos rolo de papel com terra com três dias de exposição nas temperaturas de $10^{\circ} \mathrm{C}$ e $15^{\circ} \mathrm{C}$ e rolo de papel sem terra, com sete dias de exposição à $10^{\circ} \mathrm{C}$.

As maiores correlações da metodologia do teste de frio e emergência em campo ocorreram com os tratamentos rolo de papel com terra com três dias de exposição à $10^{\circ} \mathrm{C}$, com rolo de papel sem terra, com cinco dias de exposição à $15^{\circ} \mathrm{C}$ e rolo de papel com terra, com sete dias de exposição à $15^{\circ} \mathrm{C}$, que apresentaram correlações de 0,68 ; 0,66 e 0,61 , respectivamente.

Para os demais testes a correlação foi muito baixa, com exceção do tratamento caixa, com sete dias de exposição à $15^{\circ} \mathrm{C}$ que apresentou correlação de 0,71 com o envelhecimento acelerado. 
De maneira geral, as metodologias que não envolveram terra (rolo de papel sem terra), mostraram maiores correlações com os outros testes de vigor, devido a menor variabilidade de resultados. FRATIN (1987), trabalhando com sementes de milho, obteve coeficientes de variação significativamente menores para os testes de frio realizados sem terra do que quando realizado com terra, demonstrando assim maior uniformidade dos resultados entre as repetições. Obteve ainda, no teste de frio sem terra, menor severidade em função da ausência ou menor incidência de microrganismos prejudiciais. Resultados semelhantes foram obtidos por CAMPOS (1998) trabalhando com sementes de arroz, onde a metodologia de rolo de papel sem terra, com período de exposição de sete dias e sob temperatura de $10^{\circ} \mathrm{C}$, mostrou o maior número de correlações com outros testes de vigor, como os de condutividade elétrica e emergência em campo. Essa menor variabilidade de resultados pela metodologia de rolo de papel sem terra é, segundo LOEFFLER et al. (1985), proporcionada pela não utilização de terra e, assim, permitindo uma avaliação direta dos efeitos de baixa temperatura e alto teor de água nas sementes, sem a interferência de outros fatores. Dessa forma os efeitos são menos drásticos que os observados em metodologias com terra. Nesse caso não existe a interferência da microbiota presente no solo, o que pode facilitar a padronização da metodologia e a uniformidade de resultados obtidos entre laboratórios e entre analistas (CICERO e VIEIRA, 1994).

As baixas correlações observadas em algumas situações não podem ser consideradas como falta de associação entre alguns testes de vigor e as metodologias do teste de frio. Para que a correlação possa ser efetivamente usada para decidir a melhor metodologia, um número maior de lotes com diferentes qualidades fisiológicas devem ser testados para uma precisão maior da medida de correlação. No entanto, os resultados observados no presente trabalho discriminaram as metodologias de teste de frio que, numa próxima etapa, poderão ser utilizadas para aferir qual ou quais delas devem ser recomendadas para sementes de feijão. 
Tabela 9. Valores de correlação entre as diferentes metodologias do teste de frio e primeira contagem de germinação (PCG), envelhecimento acelerado (EA), condutividade elétrica (CE) e emergência em campo (EC).

\begin{tabular}{|c|c|c|c|c|}
\hline Tratamentos & PCG & $\mathbf{E A}$ & CE & EC \\
\hline $\mathrm{Cx} 7 \mathrm{D} 10^{\circ} \mathrm{C}$ & 0,33 & $-0,16$ & 0,18 & 0,16 \\
\hline $\mathrm{Cx} 7 \mathrm{D} 15^{\circ} \mathrm{C}$ & 0,51 & 0,71 & 0,21 & 0,25 \\
\hline $\mathrm{Cx} 5 \mathrm{D} 10^{\circ} \mathrm{C}$ & $-0,05$ & 0,20 & 0,10 & $-0,25$ \\
\hline $\mathrm{Cx} 5 \mathrm{D} 15^{\circ} \mathrm{C}$ & 0,38 & 0,34 & $-0,01$ & 0,08 \\
\hline $\mathrm{C} \times 3 \mathrm{D} 10^{\circ} \mathrm{C}$ & 0,58 & 0,25 & $-0,14$ & 0,27 \\
\hline $\mathrm{Cx} 3 \mathrm{D} 15^{\circ} \mathrm{C}$ & 0,28 & 0,33 & $-0,06$ & $-0,18$ \\
\hline RPCT $7 \mathrm{D} 10^{\circ} \mathrm{C}$ & 0,70 & 0,58 & $-0,11$ & 0,35 \\
\hline RPCT 7D $15^{\circ} \mathrm{C}$ & 0,17 & 0,05 & $-0,11$ & 0,61 \\
\hline RPCT $5 \mathrm{D} 10^{\circ} \mathrm{C}$ & 0,23 & $-0,11$ & 0,48 & 0,38 \\
\hline RPCT 5D $15^{\circ} \mathrm{C}$ & 0,31 & 0,05 & 0,32 & 0,30 \\
\hline RPCT $3 \mathrm{D} 10^{\circ} \mathrm{C}$ & 0,61 & $-0,15$ & 0,14 & 0,68 \\
\hline RPCT 3D $15^{\circ} \mathrm{C}$ & 0,62 & $-0,03$ & 0,16 & 0,39 \\
\hline RPST 7D $10^{\circ} \mathrm{C}$ & 0,64 & $-0,42$ & 0,27 & 0,47 \\
\hline RPST 7D $15^{\circ} \mathrm{C}$ & 0,52 & 0,22 & 0,28 & 0,31 \\
\hline RPST 5D $10^{\circ} \mathrm{C}$ & 0,77 & $-0,22$ & 0,23 & 0,51 \\
\hline RPST 5D $15^{\circ} \mathrm{C}$ & 0,74 & 0,07 & 0,09 & 0,66 \\
\hline RPST 3D $10^{\circ} \mathrm{C}$ & 0,80 & $-0,29$ & 0,33 & 0,57 \\
\hline RPST 3D $15^{\circ} \mathrm{C}$ & 0,84 & $-0,08$ & 0,18 & 0,53 \\
\hline
\end{tabular}

\subsection{Sementes de soja}

A análise da variância para sementes de soja, cultivar FT-5, na primeira época mostrou não haver diferença significativa entre as diferentes metodologias do teste de frio para o lote 1. Já para os lotes 2 e 3 , o teste revelou haver pelo menos uma diferença entre as metodologias. Na Tabela 10, observa-se a correlação entre médias pelo teste de Tukey para as diferentes metodologias. Para o lote 2, o tratamento que proporcionou maior redução de emergência de plântulas foi o tratamento que envolveu caixa, com sete dias de exposição à $15^{\circ} \mathrm{C}$, cujo tratamento diferiu significativamente dos demais, seguido de caixa, com três dias à $10^{\circ} \mathrm{C}$, mas que não diferiu de outros tratamentos. $\mathrm{O}$ tratamento que apresentou maior percentual de emergência foi o rolo de papel sem terra com três dias à $10^{\circ} \mathrm{C}$ mas, apesar disso, não diferiu significativamente de 
outros tratamentos. De maneira geral, para o lote 3, as diferenças entre as metodologias do teste de frio foram pequenas, mostrando que o tratamento caixa, com cinco dias à $15^{\circ} \mathrm{C}$, apresentou menor percentual de emergência diferindo significativamente apenas do rolo de papel com terra, com três dias de exposição à $10^{\circ} \mathrm{C}$, do rolo de papel sem terra, com cinco dias e três dias de exposição à $10^{\circ} \mathrm{C}$.

Tabela 10 - Médias ${ }^{1}(\%)$ e coeficientes de variação $(\%)$ referentes às diferentes metodologias do teste de frio realizados nos lotes de sementes de soja, cultivar FT-5, observados na $1^{\text {a }}$ época.

\begin{tabular}{|c|c|c|c|}
\hline Tratamentos $^{2}$ & Lote 1 & Lote 2 & Lote 3 \\
\hline $\mathrm{Cx} 7 \mathrm{D} 10^{\circ} \mathrm{C}$ & 77,6 a & 68,6 & $84,0 \mathrm{ab}$ \\
\hline $\mathrm{C} \times 7 \mathrm{D} 15^{\circ} \mathrm{C}$ & 82,3 a & 42,4 & $79,3 \mathrm{ab}$ \\
\hline $\mathrm{Cx} 5 \mathrm{D} 10^{\circ} \mathrm{C}$ & 80,0 a & 69,1 & $82,1 \mathrm{ab}$ \\
\hline $\mathrm{Cx} 5 \mathrm{D} 15^{\circ} \mathrm{C}$ & 82,1 a & 75,6 & $74,3 \quad b$ \\
\hline $\mathrm{Cx} 3 \mathrm{D} 10^{\circ} \mathrm{C}$ & 79,4 a & 66,5 & $91,1 \mathrm{ab}$ \\
\hline $\mathrm{Cx} 3 \mathrm{D} 15^{\circ} \mathrm{C}$ & 87,2 a & 75,3 & $86,3 \mathrm{ab}$ \\
\hline RPCT $7 D 10^{\circ} \mathrm{C}$ & 84,4 a & 79,2 abcde & $88,0 \mathrm{ab}$ \\
\hline RPCT $7 D 15^{\circ} \mathrm{C}$ & 82,9 a & 82,5 abcd & $85,4 a b$ \\
\hline RPCT $5 \mathrm{D} 10^{\circ} \mathrm{C}$ & 85,6 a & 79,2 abcde & $90,9 \mathrm{ab}$ \\
\hline RPCT $5 D 15^{\circ} \mathrm{C}$ & 81,5 a & 78,0 abcde & $85,8 \mathrm{ab}$ \\
\hline RPCT $3 D 10^{\circ} \mathrm{C}$ & 83,2 a & $86,8 \mathrm{abc}$ & 93,7 a \\
\hline $\mathrm{RPCT} 3 \mathrm{D} 15^{\circ} \mathrm{C}$ & 88,7 a & 81,0 abcde & $90,7 \mathrm{ab}$ \\
\hline RPST TD $10^{\circ} \mathrm{C}$ & 77,3 a & $87,9 \mathrm{abc}$ & $90,1 \mathrm{ab}$ \\
\hline RPST $7 D 15^{\circ} \mathrm{C}$ & 80,7 a & 76,6 bcde & $90,6 a b$ \\
\hline RPST $5 \mathrm{D} 10^{\circ} \mathrm{C}$ & 88,2 a & $89,9 \mathrm{ab}$ & 92,1 a \\
\hline RPST $5 D 15^{\circ} \mathrm{C}$ & 78,1 a & 77,3 abcde & $89,5 \mathrm{ab}$ \\
\hline RPST $3 \mathrm{D} 10^{\circ} \mathrm{C}$ & 81,1 a & 90,5 a & 92,4 a \\
\hline RPST 3D $15^{\circ} \mathrm{C}$ & 77,1 a & $86,1 \mathrm{abc}$ & $91,3 \mathrm{ab}$ \\
\hline C.V. & 6,7 & 6,5 & 7,6 \\
\hline
\end{tabular}

${ }^{1}$ Médias seguidas por letras distintas na coluna diferem entre si pelo teste de Tukey, ao nivel de $5 \%$ de significância.

${ }^{2} \mathrm{Cx}=$ Caixa; RPCT $=$ Rolo de papel com terra; RPST $=$ rolo de papel sem terra e $\mathrm{D}=$ dias de exposição.

$\mathrm{Na}$ Tabela 11, encontram-se as médias de emergência do cultivar FT-5 submetidas às diferentes metodologias do teste de frio na segunda época. Nesta Tabela, observa-se que no lote 1 , todos os tratamentos que envolveram rolo de papel sem terra proporcionaram as maiores emergências, caracterizando-se como menos drásticos. Por estes resultados, verifica-se que, independente do tempo de exposição ou da 
temperatura, o rolo de papel sem terra não proporcionou um estresse muito acentuado nas sementes. No entanto, segundo WATERS e BLANCHETTE (1983), a emergência de plântulas em rolo de papel sem terra pode ser interessante como um teste prático para medir o efeito do estresse causado pelo frio, pois requer menos espaço e tempo que testes com areia ou terra. O tratamento mais drástico envolveu rolo de papel com terra, com sete dias de exposição à $10^{\circ} \mathrm{C}$, apesar de não ter diferido de outros tratamentos.

Para o lote 2, resultados semelhantes foram observados, pois o rolo de papel sem terra, independente do tempo de exposição e da temperatura, revelou as maiores emergências diferindo significativamente dos demais tratamentos. É possível observar que o teste separou dois grupos distintos, sendo que, todos os tratamentos com caixa, ou com rolo de papel com terra, não diferiram significativamente entre si. Para o lote 3 , novamente foi observado que os tratamentos que envolveram rolo de papel sem terra apresentaram valores mais altos e diferiram significativamente dos demais tratamentos. O tratamento onde a emergência foi menor, correspondeu ao tratamento com caixa, com exposição de sete dias à $15^{\circ} \mathrm{C}$.

A análise para o cultivar BR-16, na primeira época (Tabela 12), permite verificar diferenças significativas entre as metodologias do teste de frio para os lotes 1 e 2 , não revelando diferenças significativas para o lote 3 . De modo geral, as metodologias que proporcionaram maior redução de emergência para o lote 1, foram aquelas nas quais o substrato utilizado foi a caixa, independente do tempo de exposição e da temperatura. No tratamento rolo de papel sem terra, com sete dias de exposição a $10^{\circ} \mathrm{C}$, obteve-se a maior emergência entre as metodologias estudadas do teste de frio, embora não tenha diferido significativamente de outros tratamentos. 
Tabela 11 - Médias ${ }^{1}(\%)$ e coeficientes de variação (\%) referentes às diferentes metodologias do teste de frio realizados nos lotes de sementes de soja, cultivar FT-5, observados na $2^{\mathrm{a}}$ época.

\begin{tabular}{|c|c|c|c|c|}
\hline Tratamentos ${ }^{2}$ & Lote 1 & Lote 2 & \multicolumn{2}{|c|}{ Lote 3} \\
\hline $\mathrm{Cx} 7 \mathrm{D} 10^{\circ} \mathrm{C}$ & 7,1 & 0,0 & 1,1 & fgh \\
\hline $\mathrm{Cx} 7 \mathrm{D} 15^{\circ} \mathrm{C}$ & 20,0 & 0,0 & 0,0 & $\mathrm{~h}$ \\
\hline $\mathrm{Cx} 5 \mathrm{D} 10^{\circ} \mathrm{C}$ & 10,9 & 0,0 & 0,5 & gh \\
\hline $\mathrm{Cx}$ 5D $15^{\circ} \mathrm{C}$ & 20,7 & $0,5 \mathrm{c}$ & 8,4 & def \\
\hline $\mathrm{Cx} 3 \mathrm{D} 10^{\circ} \mathrm{C}$ & 16,1 & 0,0 & 1,7 & efgh \\
\hline $\mathrm{Cx} 3 \mathrm{D} 15^{\circ} \mathrm{C}$ & $28,3 \quad b c$ & $0,5 \mathrm{c}$ & 2,5 & efgh \\
\hline RPCT 7D $10^{\circ} \mathrm{C}$ & 5,5 & 0,0 & 0,5 & gh \\
\hline RPCT $7 \mathrm{D} 15^{\circ} \mathrm{C}$ & 20,0 & 0,0 & 4,9 & defg \\
\hline RPCT $5 \mathrm{D} 10^{\circ} \mathrm{C}$ & $28,0 \quad b c$ & 0,9 & 4,0 & efg \\
\hline RPCT 5D $15^{\circ} \mathrm{C}$ & 18,3 & 0,0 & 2,0 & efgh \\
\hline RPCT $3 \mathrm{D} 10^{\circ} \mathrm{C}$ & $29,8 \quad b c$ & $1,5 \mathrm{c}$ & 8,5 & de \\
\hline RPCT $3 \mathrm{D} 15^{\circ} \mathrm{C}$ & $41,4 \quad b$ & $0,7 \quad \mathrm{c}$ & 15,8 & $\mathrm{~d}$ \\
\hline RPST 7D $10^{\circ} \mathrm{C}$ & 78,4 a & $53,5 \mathrm{a}$ & 70,7 & \\
\hline RPST 7D $15^{\circ} \mathrm{C}$ & $63,6 \mathrm{a}$ & $25,8 \quad b$ & 51,0 & $\mathrm{c}$ \\
\hline RPST $5 \mathrm{D} 10^{\circ} \mathrm{C}$ & $80,6 \mathrm{a}$ & 48,5 a & 75,1 & \\
\hline RPST $5 D 15^{\circ} \mathrm{C}$ & 75,6 a & $29,2 \quad b$ & 53,5 & $b c$ \\
\hline RPST $3 D 10^{\circ} \mathrm{C}$ & $72,7 \mathrm{a}$ & $43,0 \mathrm{ab}$ & 58,0 & $b c$ \\
\hline RPST $3 D 15^{\circ} \mathrm{C}$ & $77,6 \mathrm{a}$ & $38,9 \mathrm{ab}$ & 42,5 & c \\
\hline C.V. & 12,1 & 29,6 & 17,2 & \\
\hline
\end{tabular}

Médias seguidas por letras distintas na coluna diferem entre si pelo teste de Tukey, ao nível de $5 \%$ de significância.

${ }^{2} \mathrm{CX}=$ Caixa; $\mathrm{RPCT}=$ Rolo de papel com terra; $\mathrm{RPST}=$ rolo de papel sem terra e $\mathrm{D}=$ dias de exposição.

Para o lote 2, foi obtido resultado semelhante ao lote 1, onde todas as metodologias que envolveram caixa, propiciaram as menores emergências de plântulas. Além desses tratamentos, os tratamentos de rolo de papel com terra e sete dias de exposição nas duas temperaturas também proporcionaram maiores reduções de emergência. De maneira semelhante ao lote 1 , o tratamento menos drástico às sementes de soja foi obtido com rolo de papel sem terra, com período de exposição de sete dias à $10^{\circ} \mathrm{C}$. 
Tabela 12 - Médias ${ }^{1}(\%)$ e coeficientes de variação $(\%)$ referentes às diferentes metodologias do teste de frio realizados nos lotes de sementes de soja, cultivar BR16 , observados na 1 época.

\begin{tabular}{|c|c|c|c|}
\hline Tratamentos ${ }^{2}$ & Lote 1 & Lote 2 & Lote 3 \\
\hline $\mathrm{Cx} 7 \mathrm{D} 10^{\circ} \mathrm{C}$ & 22,3 & 27,4 & $81,1 \mathrm{a}$ \\
\hline $\mathrm{Cx} 7 \mathrm{D} 15^{\circ} \mathrm{C}$ & 35,3 & 20,8 & 85,6 a \\
\hline $\mathrm{Cx} 5 \mathrm{D} 10^{\circ} \mathrm{C}$ & 39,4 & 42,0 & $87,7 \mathrm{a}$ \\
\hline $\mathrm{Cx} 5 \mathrm{D} 15^{\circ} \mathrm{C}$ & 25,3 & 30,8 & $90,2 \mathrm{a}$ \\
\hline $\mathrm{Cx} 3 \mathrm{D} 10^{\circ} \mathrm{C}$ & 37,0 & 34,8 & $80,0 \mathrm{a}$ \\
\hline $\mathrm{C} \times 3 \mathrm{D} 15^{\circ} \mathrm{C}$ & 38,8 & 24,9 & 77,9 a \\
\hline RPCT $7 \mathrm{D} 10^{\circ} \mathrm{C}$ & $62,6 \quad b c$ & 49,0 & 84,6 a \\
\hline RPCT $7 \mathrm{D} 15^{\circ} \mathrm{C}$ & $55,5 \quad \mathrm{~cd}$ & 31,3 & 76,2 a \\
\hline RPCT $5 \mathrm{D} 10^{\circ} \mathrm{C}$ & $66,1 \quad b c$ & 64,1 bcd & 85,2 a \\
\hline RPCT 5D $15^{\circ} \mathrm{C}$ & $62,6 \quad b c$ & 57,5 cde & $80,7 a$ \\
\hline RPCT 3D $10^{\circ} \mathrm{C}$ & 74,2 abc & 68,0 abcd & $87,7 \mathrm{a}$ \\
\hline RPCT 3D $15^{\circ} \mathrm{C}$ & $64,1 \quad b c$ & 61,1 bcde & $88,7 a$ \\
\hline RPST 7D $10^{\circ} \mathrm{C}$ & 83,8 a & 83,4 a & 87,3 a \\
\hline RPST 7D $15^{\circ} \mathrm{C}$ & $65,3 \quad b c$ & 60,6 cde & 84,2 a \\
\hline RPST $5 \mathrm{D} 10^{\circ} \mathrm{C}$ & $79,1 \mathrm{ab}$ & $77,1 \mathrm{abc}$ & 88,1 a \\
\hline RPST 5D $15^{\circ} \mathrm{C}$ & $69,6 \mathrm{abc}$ & $80,8 \mathrm{ab}$ & 84,1 a \\
\hline RPST 3D $10^{\circ} \mathrm{C}$ & $80,3 \mathrm{ab}$ & $77,2 \mathrm{abc}$ & 87,2 a \\
\hline RPST $3 \mathrm{D} 15^{\circ} \mathrm{C}$ & $71,5 \mathrm{abc}$ & $76,6 \mathrm{abc}$ & $78,6 a$ \\
\hline C.V. & 9,2 & 10,3 & 7,3 \\
\hline
\end{tabular}

$\mathrm{Na}$ análise realizada na segunda época para o cultivar BR-16, verificou-se que para os três lotes estudados, o teste de Tukey (Tabela 13) detectou diferença significativa entre as diferentes metodologias do teste de frio. Para o lote 1 , apenas os tratamentos com rolo de papel sem terra nos diferentes períodos de exposição e temperaturas, proporcionaram emergência de plântulas. Nos demais tratamentos a emergência não ocorreu, mostrando assim que os tratamentos que envolveram caixa e rolo de papel com terra foram muito drásticos para as sementes de soja utilizadas na presente pesquisa.

No entanto, há de se considerar que, na segunda época ocorreu acentuada queda na qualidade fisiológica das sementes. Assim, qualquer metodologia que 
proporcionasse condição de estresse um pouco mais intensa, provocaria uma acentuada redução dos valores de emergência.

Para o lote 2, nem todos os tratamentos que envolveram rolo de papel sem terra proporcionaram emergência de plântulas, sendo que mesmo naqueles em que houve emergência, esta foi muito baixa. Para o lote 3 , assim como no lote 1 , os tratamentos de rolo de papel sem terra foram os únicos a revelar valores de emergência de plântulas; nos demais tratamentos, a emergência não ocorreu. Nesta segunda época, a exceção do rolo de papel sem terra, os demais não proporcionaram emergência de plântulas, não sendo possível assim, detectar diferença entre as metodologias.

Tabela 13 - Médias ${ }^{1}(\%)$ e coeficientes de variação $(\%)$ referentes às diferentes metodologias do teste de frio realizados nos lotes de sementes de soja, cultivar BR16 , observados na $2^{\mathrm{a}}$ época.

\begin{tabular}{|c|c|c|c|}
\hline Tratamentos ${ }^{2}$ & Lote 1 & Lote 2 & Lote 3 \\
\hline $\mathrm{Cx} 7 \mathrm{D} 10^{\circ} \mathrm{C}$ & 0,0 & $0,0 \quad b$ & $0,0 \quad \mathrm{c}$ \\
\hline $\mathrm{Cx} 7 \mathrm{D} 15^{\circ} \mathrm{C}$ & 0,0 & $0,0 \quad b$ & $0,0 \mathrm{c}$ \\
\hline $\mathrm{Cx} 5 \mathrm{D} 10^{\circ} \mathrm{C}$ & 0,0 & $0,0 \quad b$ & $0,0 \mathrm{c}$ \\
\hline $\mathrm{Cx} 5 \mathrm{D} 15^{\circ} \mathrm{C}$ & 0,0 & $0,0 \quad b$ & $0,0 \mathrm{c}$ \\
\hline $\mathrm{Cx} 3 \mathrm{D} 10^{\circ} \mathrm{C}$ & 0,0 & $0,0 \quad b$ & $0,0 \quad \mathrm{c}$ \\
\hline $\mathrm{Cx} 3 \mathrm{D} 15^{\circ} \mathrm{C}$ & 0,0 & $0,0 \quad \mathrm{~b}$ & $0,0 \mathrm{c}$ \\
\hline RPCT $7 D 10^{\circ} \mathrm{C}$ & 0,0 & $0,0 \quad b$ & $0,0 \mathrm{c}$ \\
\hline RPCT $7 \mathrm{D} 15^{\circ} \mathrm{C}$ & 0,0 & $0,0 \quad b$ & $0,0 \mathrm{c}$ \\
\hline RPCT $5 \mathrm{D} 10^{\circ} \mathrm{C}$ & 0,0 & $0,0 \quad b$ & $0,0 \mathrm{c}$ \\
\hline RPCT $5 D 15^{\circ} \mathrm{C}$ & 0,0 & $0,0 \quad b$ & $0,0 \quad \mathrm{c}$ \\
\hline RPCT $3 \mathrm{D} 10^{\circ} \mathrm{C}$ & 0,0 & $0,0 \quad b$ & $0,0 \mathrm{c}$ \\
\hline RPCT $3 \mathrm{D} 15^{\circ} \mathrm{C}$ & 0,0 & $0,0 \quad b$ & $0,0 \mathrm{c}$ \\
\hline RPST 7D $10^{\circ} \mathrm{C}$ & $6,8 \mathrm{ab}$ & $2,9 \mathrm{a}$ & $29,9 \mathrm{a}$ \\
\hline RPST $7 D 15^{\circ} \mathrm{C}$ & $0,5 \quad c$ & $0,0 \quad b$ & $25,8 \mathrm{ab}$ \\
\hline RPST $5 \mathrm{D} 10^{\circ} \mathrm{C}$ & $9,3 \mathrm{a}$ & $2,5 \mathrm{a}$ & $30,8 \mathrm{a}$ \\
\hline RPST 5D $15^{\circ} \mathrm{C}$ & $4,3 \mathrm{ab}$ & $0,0 \quad b$ & $25,5 \mathrm{ab}$ \\
\hline RPST $3 \mathrm{D} 10^{\circ} \mathrm{C}$ & $3,3 \quad b$ & $0,0 \quad b$ & $18,3 \quad b$ \\
\hline RPST 3D $15^{\circ} \mathrm{C}$ & $5,5 \mathrm{ab}$ & $3,3 \mathrm{a}$ & $22,5 \mathrm{ab}$ \\
\hline C.V. & 19,6 & 10,3 & 24,0 \\
\hline
\end{tabular}

${ }^{\text {Médias seguidas por letras distintas na coluna diferem entre si pelo teste de Tukey, ao nível de } 5 \% \text { de }}$ significância.

${ }^{2} \mathrm{Cx}=\mathrm{Caixa} ; \mathrm{RPCT}=$ Rolo de papel com terra; $\mathrm{RPST}=$ rolo de papel sem terra e $\mathrm{D}=$ dias de exposição. 
Para o cultivar Ocepar-13, na primeira época (Tabela 14), o teste de Tukey detectou diferenças significativas para as metodologias estudadas. Para o lote 1 , foi observado o mesmo comportamento do cultivar BR-16 com relação aos tratamentos mais drásticos; observou-se a mesma tendência para os tratamentos com caixa e rolo de papel com terra, com ambos apresentando baixos valores de emergência.

Para o lote 2, o tratamento caixa, com cinco dias de exposição à $15^{\circ} \mathrm{C}$, proporcionou maior redução de emergência de plântulas. De acordo com POLLOCK e TOOLE (1966), durante a embebição à baixa temperatura, pode ocorrer lixiviação de materiais orgânicos, possivelmente nucleotídeos, o que irá influenciar sobre os microrganismos do solo, que juntamente com a temperatura, nível de vigor e a cobertura protetora da sementes exercem controle sobre o efeito de baixas temperaturas na emergência das plântulas. Deve-se ressaltar ainda, que a atividade microbiana afeta o início do estabelecimento da cultura, principalmente em condições de baixa temperatura e alta umidade do solo (CICERO e VIEIRA, 1994).

$\mathrm{O}$ maior valor de emergência verificado foi através da metodologia rolo de papel sem terra, com três dias de exposição à $10^{\circ} \mathrm{C}$. Segundo LOEFFLER et al. (1985), o rolo de papel sem terra é menos drástico em função de avaliar diretamente os efeitos da baixa temperatura e alta umidade, sem a interferência de outros fatores, como por exemplo, a microbiota do solo.

No lote 3, foi possivel observar três grupos importantes, sendo o primeiro formado pelas maiores emergências detectadas nos tratamentos com rolo de papel sem terra, um segundo grupo intermediário, que correspondeu ao rolo de papel com terra e um terceiro grupo correspondente ao tratamento que envolveu caixa. 
Tabela 14 - Médias ${ }^{1}(\%)$ e coeficientes de variação $(\%)$ referentes às diferentes metodologias do teste de frio realizados nos lotes de sementes de soja, cultivar OCEPAR-13, observados na $1^{2}$ época.

\begin{tabular}{|c|c|c|c|}
\hline Tratamentos $^{2}$ & Lote 1 & Lote 2 & Lote 3 \\
\hline $\mathrm{Cx} 7 \mathrm{D} 10^{\circ} \mathrm{C}$ & 53,7 & 46,4 & 39,0 \\
\hline $\mathrm{Cx} 7 \mathrm{D} 15^{\circ} \mathrm{C}$ & 49,0 & cdef & 37,5 \\
\hline $\mathrm{Cx} 5 \mathrm{D} 10^{\circ} \mathrm{C}$ & 58,9 & 47,5 & 34,0 \\
\hline $\mathrm{Cx} 5 \mathrm{D} 15^{\circ} \mathrm{C}$ & 49,9 & 29,1 & 28,8 \\
\hline $\mathrm{Cx} 3 \mathrm{D} 10^{\circ} \mathrm{C}$ & 56,5 & 64,6 bcdef & 37,8 \\
\hline $\mathrm{Cx} 3 \mathrm{D} 15^{\circ} \mathrm{C}$ & 60,5 bcdef & 50,5 & 37,9 \\
\hline RPCT 7D $10^{\circ} \mathrm{C}$ & 73,6 abcde & 66,8 bcdef & $50,4 \mathrm{bcd}$ \\
\hline RPCT $7 \mathrm{D} 15^{\circ} \mathrm{C}$ & 59,3 & 51,5 & 41,9 \\
\hline RPCT $5 \mathrm{D} 10^{\circ} \mathrm{C}$ & 73,5 abcde & $79,4 \mathrm{ab}$ & $66,6 a b$ \\
\hline RPCT 5D $15^{\circ} \mathrm{C}$ & 69,4 abcdef & 65,5 bcdef & $64,0 \mathrm{ab}$ \\
\hline RPCT $3 D 10^{\circ} \mathrm{C}$ & 83,7 a & $83,2 \mathrm{ab}$ & $69,0 \mathrm{ab}$ \\
\hline RPCT 3D $15^{\circ} \mathrm{C}$ & $78,6 \mathrm{abc}$ & $72,3 \mathrm{abcd}$ & 58,1 abc \\
\hline RPST 7D $10^{\circ} \mathrm{C}$ & $79,3 \mathrm{abc}$ & $80,8 \mathrm{ab}$ & $75,8 \mathrm{a}$ \\
\hline RPST 7D $15^{\circ} \mathrm{C}$ & $76,5 \mathrm{abcd}$ & 71,5 abcde & $69,3 \mathrm{a}$ \\
\hline RPST $5 \mathrm{D} 10^{\circ} \mathrm{C}$ & $82,6 \mathrm{ab}$ & $83,1 \mathrm{ab}$ & 74,5 a \\
\hline RPST $5 \mathrm{D} 15^{\circ} \mathrm{C}$ & $78,1 \mathrm{abc}$ & 69,8 abcde & $68,6 a b$ \\
\hline RPST 3D $10^{\circ} \mathrm{C}$ & 86,7 a & $85,6 \mathrm{a}$ & $72,5 \mathrm{a}$ \\
\hline RPST $3 D 15^{\circ} \mathrm{C}$ & $75,1 \mathrm{abcd}$ & $73,2 \mathrm{abc}$ & $62,1 \mathrm{ab}$ \\
\hline C.V. & 9,7 & 9,0 & 8,8 \\
\hline
\end{tabular}

Médias seguidas por letras distintas na coluna diferem entre si pelo teste de Tukey, ao nivel de $5 \%$ de significância.

${ }^{2} \mathrm{Cx}=$ Caixa; $\mathrm{RPCT}=$ Rolo de papel com terra; $\mathrm{RPST}=$ rolo de papel sem terra e $\mathrm{D}=$ dias de exposição.

Na segunda época (Tabela 15), o cultivar Ocepar 13, revelou o mesmo comportamento verificado na primeira época, ou seja, para os lotes 1,2 e 3 , os tratamentos mais drásticos envolveram o substrato caixa e rolo de papel com terra. A diminuição da emergência não pode ser atribuída neste caso somente às metodologias utilizadas, pois os lotes na segunda época apresentaram baixa germinação, o que pode ser constatado na Tabela 19. 
Tabela 15 - Médias ${ }^{1}(\%)$ e coeficientes de variação $(\%)$ referentes às diferentes metodologias do teste de frio realizados nos lotes de sementes de soja, cultivar OCEPAR-13, observados na $2^{\mathrm{a}}$ época.

\begin{tabular}{|c|c|c|c|c|c|}
\hline Tratamentos ${ }^{2}$ & \multicolumn{2}{|c|}{ Lote 1} & \multicolumn{2}{|l|}{ Lote 2} & Lote 3 \\
\hline $\mathrm{C} \times 7 \mathrm{D} 10^{\circ} \mathrm{C}$ & 0,0 & $\mathrm{~g}$ & 0,0 & $\mathrm{~d}$ & $0,0 \quad \mathrm{~b}$ \\
\hline $\mathrm{Cx} 7 \mathrm{D} 15^{\circ} \mathrm{C}$ & 0,0 & $\mathrm{~g}$ & 0,0 & $\mathrm{~d}$ & $0,0 \mathrm{~b}$ \\
\hline $\mathrm{Cx} 5 \mathrm{D} 10^{\circ} \mathrm{C}$ & 0,0 & $\mathrm{~g}$ & 0,0 & $\mathrm{~d}$ & $0,0 \quad \mathrm{~b}$ \\
\hline $\mathrm{C} \times 5 \mathrm{D} 15^{\circ} \mathrm{C}$ & 0,0 & $\mathrm{~g}$ & 0,0 & $\mathrm{~d}$ & $0,0 \quad \mathrm{~b}$ \\
\hline $\mathrm{C} \times 3 \mathrm{D} 10^{\circ} \mathrm{C}$ & 0,0 & $\mathrm{~g}$ & 0,0 & $\mathrm{~d}$ & $0,0 \quad \mathrm{~b}$ \\
\hline $\mathrm{Cx} 3 \mathrm{D} 15^{\circ} \mathrm{C}$ & 0,0 & $\mathrm{~g}$ & 0,0 & $\mathrm{~d}$ & $0,0 \mathrm{~b}$ \\
\hline RPCT 7D $10^{\circ} \mathrm{C}$ & 0,0 & g & 0,0 & $\mathrm{~d}$ & $0,0 \mathrm{~b}$ \\
\hline RPCT 7D $15^{\circ} \mathrm{C}$ & 0,0 & $\mathrm{~g}$ & 0,0 & $\mathrm{~d}$ & $0,0 \mathrm{~b}$ \\
\hline RPCT $5 \mathrm{D} 10^{\circ} \mathrm{C}$ & 0,0 & $\mathrm{~g}$ & 0,0 & $\mathrm{~d}$ & $0,0 \mathrm{~b}$ \\
\hline RPCT $5 D 15^{\circ} \mathrm{C}$ & 0,0 & g & 0,0 & $\mathrm{~d}$ & $0,0 \mathrm{~b}$ \\
\hline RPCT 3D $10^{\circ} \mathrm{C}$ & 2,4 & ef & 0,5 & $\mathrm{~cd}$ & $0,0 \quad b$ \\
\hline RPCT 3D $15^{\circ} \mathrm{C}$ & 2,0 & $\mathrm{f}$ & 0,0 & $\mathrm{~d}$ & $0,0 \mathrm{~b}$ \\
\hline RPST 7D $10^{\circ} \mathrm{C}$ & 17,9 & & $14,6 \mathrm{a}$ & & $6,8 \mathrm{a}$ \\
\hline RPST $7 D 15^{\circ} \mathrm{C}$ & 5,6 & de & $2,9 \mathrm{bc}$ & & $0,0 \mathrm{~b}$ \\
\hline RPST $5 \mathrm{D} 10^{\circ} \mathrm{C}$ & 21,8 & & $14,2 \mathrm{a}$ & & 3,1 a \\
\hline RPST $5 \mathrm{D} 15^{\circ} \mathrm{C}$ & 9,4 & $\mathrm{~cd}$ & $6,5 \mathrm{ab}$ & & $4,7 \mathrm{a}$ \\
\hline RPST $3 \mathrm{D} 10^{\circ} \mathrm{C}$ & 22,8 & & $11,4 \mathrm{a}$ & & $1,8 \mathrm{a}$ \\
\hline RPST $3 \mathrm{D} 15^{\circ} \mathrm{C}$ & 13,4 & & $9,1 \mathrm{ab}$ & & $1,7 \mathrm{ab}$ \\
\hline C.V. & 24,3 & & 20,9 & & 19,6 \\
\hline
\end{tabular}

${ }^{T}$ Médias seguidas por letras distintas na coluna diferem entre si pelo teste de Tukey, ao nível de $5 \%$ de significância.

${ }^{2} \mathrm{CX}=$ Caixa; $\mathrm{RPCT}=$ Rolo de papel com terra; $\mathrm{RPST}=$ rolo de papel sem terra e $\mathrm{D}=$ dias de exposição.

Diferentemente do ocorrido com as sementes de feijão, não houve problemas de infestação para as sementes de soja com os patógenos Rhizoctonia solani e Fusarium spp. Os resultados da análise de sanidade de sementes e da terra utilizada nos testes de frio podem ser observados nas Tabelas 16 e 17. 

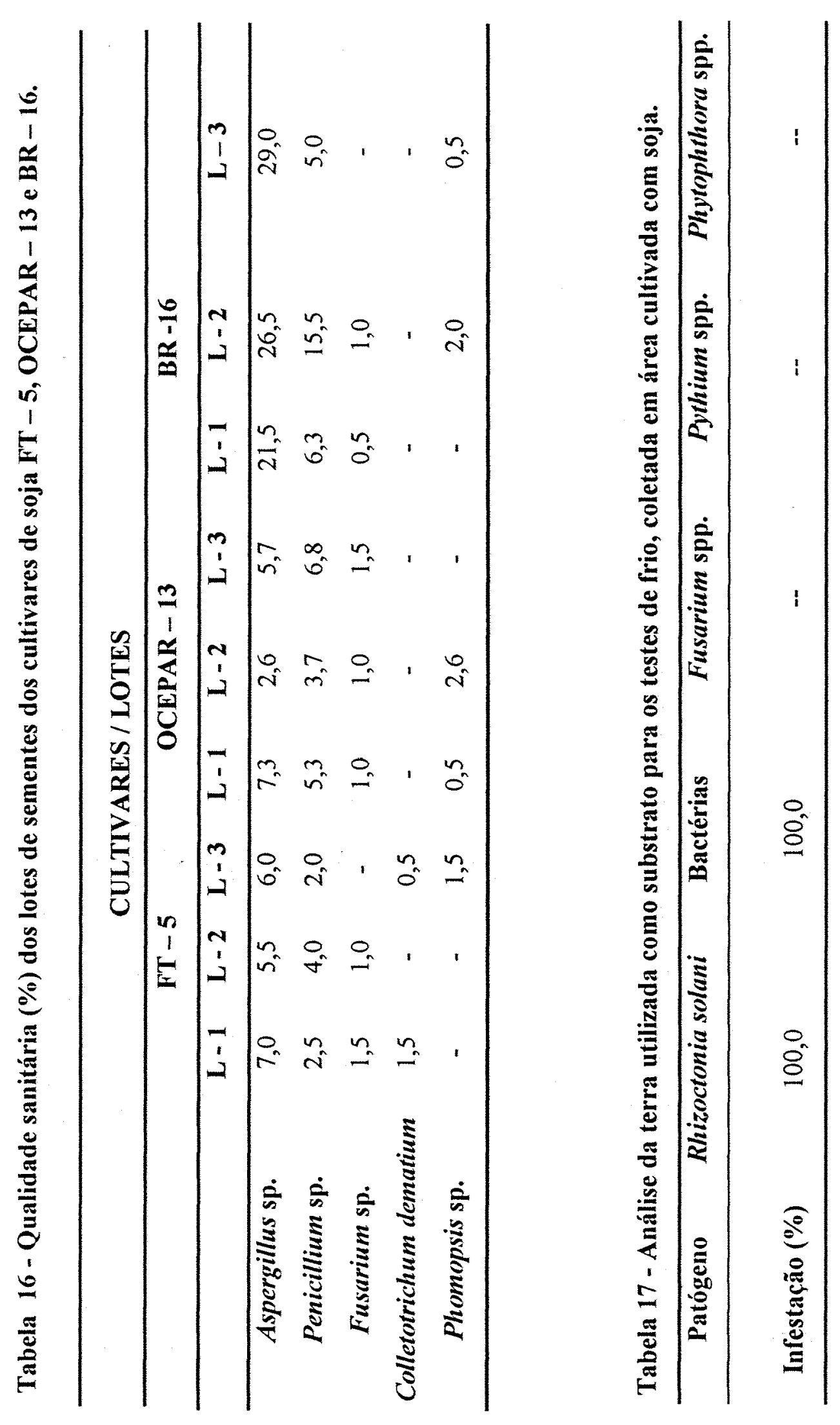
Para comparar os dados relativos aos outros testes de vigor (Tabelas $18 \mathrm{e}$ 19) em relação às diferentes metodologias do teste de frio, foi realizado teste de correlação. Na Tabela 20 , pode-se observar que, ao contrário do que encontrado para sementes de feijão, as sementes de soja apresentaram, de maneira geral, altas correlações com os demais testes de vigor.

Tabela 18 - Grau de umidade (GU), germinação (G), primeira contagem de germinação (PCG), envelhecimento acelerado (EA), condutividade elétrica (CE) e emergência em campo (EC) dos lotes de sementes de soja, cultivares FT-5 (FT-5), OCEPAR 13 (OC-13) e BR-16 (BR-16), observados na $1^{2}$ época.

\begin{tabular}{lcccccc}
\hline Cultivar/Lote & $\begin{array}{c}\text { GU } \\
(\%)\end{array}$ & $\begin{array}{c}\text { G } \\
(\%)\end{array}$ & $\begin{array}{c}\text { PCG } \\
(\%)\end{array}$ & $\begin{array}{c}\text { EA } \\
(\%)\end{array}$ & $\begin{array}{c}\text { CE } \\
(\boldsymbol{\%} \text { (\%mos/cm/g) }\end{array}$ & $\begin{array}{c}\text { EC } \\
(\%)\end{array}$ \\
\hline FT-5 - L1 & 11,4 & 87 & 76 & 77 & 91 & 80 \\
FT-5-L2 & 11,0 & 92 & 80 & 73 & 98 & 62 \\
FT-5-L3 & 10,9 & 97 & 92 & 88 & 75 & 74 \\
\hline BR-16-L1 & 11,5 & 87 & 78 & 51 & 132 & 54 \\
BR-16-L2 & 11,8 & 88 & 82 & 28 & 137 & 39 \\
BR-16-L3 & 11,2 & 96 & 92 & 88 & 86 & 80 \\
\hline OC-13-L1 & 11,0 & 92 & 90 & 75 & 95 & 65 \\
OC-13-L2 & 11,6 & 97 & 89 & 66 & 100 & 58 \\
OC-13-L3 & 11,3 & 94 & 80 & 35 & 107 & 52 \\
\hline
\end{tabular}

Tabela 19 - Grau de umidade (GU), germinação (G), primeira contagem de germinação (PCG), envelhecimento acelerado (EA), condutividade elétrica (CE) e emergência em campo (EC) dos lotes de sementes de soja, cultivares FT-5 (FT-5), OCEPAR 13 (OC-13) e BR-16 (BR-16), observados na $2^{\mathrm{a}}$ época.

\begin{tabular}{lcccccc}
\hline Cultivar/Lote & $\begin{array}{c}\text { GU } \\
(\%)\end{array}$ & $\begin{array}{c}\text { G } \\
(\%)\end{array}$ & $\begin{array}{c}\text { PCG } \\
(\%)\end{array}$ & $\begin{array}{c}\text { EA } \\
(\%)\end{array}$ & $\begin{array}{c}\text { CE } \\
(\boldsymbol{\mu m h o s} / \mathbf{c m} / \mathbf{g})\end{array}$ & $\begin{array}{c}\text { EC } \\
(\%)\end{array}$ \\
\hline FT-5 - L1 & 11,3 & 89 & 79 & 38 & 110 & 80 \\
FT-5-L2 & 11,2 & 59 & 44 & 4 & 144 & 53 \\
FT-5-L3 & 11,2 & 82 & 79 & 34 & 113 & 78 \\
\hline BR-16-L1 & 11,5 & 17 & 12 & 0 & 184 & 14 \\
BR-16-L2 & 11,4 & 6 & 5 & 0 & 202 & 5 \\
BR-16-L3 & 11,5 & 51 & 39 & 4 & 124 & 60 \\
\hline OC-13-L1 & 11,3 & 31 & 23 & 4 & 148 & 40 \\
OC-13-L2 & 11,4 & 26 & 24 & 2 & 171 & 25 \\
OC-13-L3 & 11,5 & 10 & 7 & 0 & 186 & 10 \\
\hline
\end{tabular}


Com relação ao teste de envelhecimento acelerado, as melhores correlações com as metodologias do teste de frio ocorreram com rolo de papel com terra e caixa, independente da temperatura e período de exposição. Esta alta correlação mostra uma característica comum entre essas metodologias do teste de frio e o envelhecimento acelerado de serem testes muito drásticos, e assim, apresentarem elevados valores das correlações. Estes resultados mostram a importância de se compreender o que o coeficiente de correlação realmente mede, pois nestes casos, testes drásticos podem não ser os mais adequados para a avaliação de vigor, apesar de apresentarem altas correlações.

As correlações entre o teste de condutividade elétrica e as metodologias do teste de frio foram negativas, em função de que a medida em que se aumentam as leituras de condutividade elétrica, diminui a qualidade fisiológica das sementes. Esta correlação se revelou maior com as metodologias que envolveram rolo de papel sem terra.

Ainda, foi verificado que a metodologia de rolo de papel sem terra apresentou as melhores correlações com a primeira contagem de germinação.

Deve-se ressaltar que, apesar de todas as correlações terem sido altas, os tratamentos de rolo de papel sem terra apresentaram também altas correlações com a emergência em campo, sendo maiores ou iguais a 0,80. A maior correlação com a emergência em campo foi observada com o tratamento rolo de papel sem terra, com cinco dias de exposição na temperatura de $10^{\circ} \mathrm{C}$. Este resultado indica que o rolo de papel sem terra apresenta grande potencial para ser uma metodologia que permitirá comparar vigor de diferentes lotes de soja.

WATERS e BLANCHETTE (1983), afirmaram que se ocorrerem altas correlações entre a metodologia do rolo de papel sem terra e a emergência em campo, esse método pode ser recomendado para estimar a emergência de plântulas em condições adversas de campo, como excesso de água e baixas temperaturas. 
Tabela 20. Valores de correlação entre as diferentes metodologias do teste de frio e primeira contagem de germinação (PCG), envelhecimento acelerado (EA), condutividade elétrica (CE) e emergência em campo (EC).

\begin{tabular}{|c|c|c|c|c|}
\hline Tratamentos & PCG & $\overline{\mathbf{E A}}$ & $\overline{C E}$ & EC \\
\hline $\mathrm{C} \times 7 \mathrm{D} 10^{\circ} \mathrm{C}$ & 0,73 & 0,93 & $-0,79$ & 0,59 \\
\hline $\mathrm{Cx} 7 \mathrm{D} 15^{\circ} \mathrm{C}$ & 0,75 & 0,94 & $-0,79$ & 0,64 \\
\hline $\mathrm{Cx} 5 \mathrm{D} 10^{\circ} \mathrm{C}$ & 0,76 & 0,94 & $-0,78$ & 0,59 \\
\hline $\mathrm{C} \times 5 \mathrm{D} 15^{\circ} \mathrm{C}$ & 0,73 & 0,93 & $-0,78$ & 0,64 \\
\hline $\mathrm{C} \times 3 \mathrm{D} 10^{\circ} \mathrm{C}$ & 0,78 & 0,95 & $-0,80$ & 0,61 \\
\hline $\mathrm{C} \times 3 \mathrm{D} 15^{\circ} \mathrm{C}$ & 0,77 & 0,96 & $-0,82$ & 0,65 \\
\hline RPCT $7 D 10^{\circ} \mathrm{C}$ & 0,78 & 0,93 & $-0,76$ & 0,56 \\
\hline $\mathrm{RPCT} 7 \mathrm{D} 15^{\circ} \mathrm{C}$ & 0,78 & 0,96 & $-0,80$ & 0,62 \\
\hline $\mathrm{RPCT} 5 \mathrm{D} 10^{\circ} \mathrm{C}$ & 0,84 & 0,93 & $-0,79$ & 0,58 \\
\hline $\operatorname{RPCT} 5 \mathrm{D} 15^{\circ} \mathrm{C}$ & 0,82 & 0,92 & $-0,78$ & 0,57 \\
\hline $\mathrm{RPCT} 3 \mathrm{D} 10^{\circ} \mathrm{C}$ & 0,85 & 0,93 & $-0,79$ & 0,58 \\
\hline $\mathrm{RPCT} 3 \mathrm{D} 15^{\circ} \mathrm{C}$ & 0,87 & 0,96 & $-0,83$ & 0,65 \\
\hline RPST $7 D 10^{\circ} \mathrm{C}$ & 0,98 & 0,85 & $-0,89$ & 0,82 \\
\hline RPST $7 D 15^{\circ} \mathrm{C}$ & 0,97 & 0,93 & $-0,93$ & 0,83 \\
\hline RPST $5 \mathrm{D} 10^{\circ} \mathrm{C}$ & 0,98 & 0,88 & $-0,92$ & 0,86 \\
\hline RPST $5 \mathrm{D} 15^{\circ} \mathrm{C}$ & 0,98 & 0,89 & $-0,89$ & 0,80 \\
\hline $\operatorname{RPST} 3 \mathrm{D} 10^{\circ} \mathrm{C}$ & 0,98 & 0,90 & $-0,90$ & 0,80 \\
\hline RPST $3 D 15^{\circ} \mathrm{C}$ & 0,96 & 0,89 & $-0,88$ & 0,79 \\
\hline
\end{tabular}

$\mathrm{CX}=$ Caixa; $\mathrm{RPCT}=$ Rolo de papel com terra; $\mathrm{RPST}=$ rolo de papel sem terra e $\mathrm{D}=$ dias de exposição.

\subsection{Considerações Gerais}

Foi possível constatar que as diferentes metodologias do teste de frio estudadas, apresentam diferenças na capacidade de avaliar o vigor das sementes de feijão e de soja.

Com relação às sementes de feijão, verificou-se que as metodologias de rolo de papel com terra, com períodos de exposição de cinco e sete dias e com temperaturas de $15^{\circ} \mathrm{C}$, propiciaram condições favoráveis ao desenvolvimento de fungos, o que pode limitar seriamente a metodologia, em função de sua drasticidade.

De maneira geral, as metodologias que não envolveram terra (rolo de papel se terra), revelaram as maiores correlações com os outros testes de vigor, devido a menor variabilidade dos resultados, com destaque para as metodologias rolo de papel 
sem terra, com períodos de exposição de três e cinco dias nas temperaturas de $10^{\circ} \mathrm{C}$ e $15^{\circ} \mathrm{C}$.

Com relação às sementes de soja, verificou-se que o número de correlações com os testes de vigor foi superior quando comparadas às sementes de feijão. De maneira geral, a maioria das metodologias do teste de frio estudadas, apresentaram boa correlação com os testes de vigor, porém dentre elas, destacam-se as de rolo de papel sem terra. Estas apresentaram maior reprodutibilidade dos resultados, devido a menor variabilidade, em função da ausência de terra.

Ainda com relação às sementes de soja, verificou-se que em função da deterioração das sementes, de uma época para outra, as metodologias que envolveram terra (caixa e rolo de papel com terra) mostraram-se muito drásticas, proporcionando condições extremamente severas, a ponto de não se constatar a emergência de plântulas.

Assim, os resultados observados no presente trabalho, evidenciaram algumas metodologias do teste de frio, como de rolo de papel sem terra, que em trabalhos futuros poderão ser melhor aferidos, por meio de um número mais representativo de lotes de sementes, para espécies de feijão e soja. 


\section{CONCLUSÕES}

A análise dos dados e a interpretação dos resultados obtidos no presente trabalho permitiram as seguintes conclusões:

- dentre as diferentes metodologias do teste de frio utilizadas para sementes de feijão, as de rolo de papel com terra, com periodos de exposição de cinco e, principalmente, sete dias, à $15^{\circ} \mathrm{C}$, proporcionaram condições favoráveis ao desenvolvimento de fungos, limitando suas utilizações;

- para sementes de feijão, as metodologias de rolo de papel sem terra, com períodos de exposição de três e cinco dias à $10^{\circ} \mathrm{C}$ e à $15^{\circ} \mathrm{C}$, proporcionaram as melhores correlações com a primeira contagem de germinação e de emergência de plântulas em campo;

- dentre as diferentes metodologias do teste de frio utilizadas para sementes de soja, as de caixa e as de rolo de papel com terra, proporcionaram reduções drásticas na emergência das plântulas, principalmente para os materiais com qualidades fisiológicas mais baixas;

- para as sementes de soja, as metodologias de rolo de papel sem terra apresentaram as melhores correlações com os testes de primeira contagem de germinação, condutividade elétrica e de emergência de plântulas em campo. 


\section{REFERÊNCIAS BIBLIOGRÁFICAS}

ABDUL-BAKI, A. A. Biochemical aspects of seed vigour. Horticultural Science, v. 15, n. 6, p. $765-771,1980$.

ASSOCIATION OF OFFICIAL SEED ANALYSTS. Seed vigour testing handbook. East Lasing, 1983. 93 p. ( Contribution, 32 ).

BARROS, A. S. R. Testes para avaliação rápida da viabilidade e do vigor de sementes de soja (Glycine max (L) Merrill). Piracicaba, 1988. 140 p. Dissertação (Mestrado) Escola Superior de Agricultura "Luiz de Queiroz ", Universidade de São Paulo.

BEDFORD, L. V. Conductivity tests in commercial and hand harvest seed of pea cultivar and their relation to field establishment. Seed Science and Technology, v. 2, n. 3, p. $323-335,1974$.

BEWLEY, J. D. Membrane change in seeds as related to germination and the perturbations resulting fron deterioration in storage. In: McDONAD Jr, M. B.; NELSON, C. J. (Ed.) Physiology of seed deterioration. Madison: CSSA, 1986. p.27-45.

BEWLEY, J. D.; BLACK, M. Seeds. Physiology of development and germination. New York: Plenum Press, 1985. 367 p. 
BITTENCOURT, S. R. M.; VIEIRA, R. D. Efeitos da combinação de diferentes temperaturas e periodos de exposição de sementes de milho no teste de envelhecimento acelerado. In: CONGRESSO BRASILEIRO DE SEMENTES, 10. Foz do Iguaçu, 1997. Resumos. Campinas: ABRATES, 1997. p.170.

BRASIL. Ministério da Agricultura. Regras para análise de sementes. Brasilia: SNAD/DNDV/CLAV, 1992. $365 \mathrm{p}$.

BROUWER, H. M.; MULDER, J. C. Reduced spenttime for the conductivity vigour test of Phaseolus vulgaris L. Journal of Seed Technology. v. 7, n. 1, p. 85-96, 1982.

BRUGGINK, H.; KRAAK, H. L.; BEKENDAM, J. Some factors affecting maize (Zea mayz L.) cold test results. Seed Science and Technology, v.19, p. 15-23, 1991.

BURRIS, J. S.; NAVRATIL, R. J. Relationship between laboratory cold test methods and field emergence in maize inbreds. Agronomy Journal, v.71, p. 985-988, 1979.

BYRUM, J. R.; COPELAND, L. O. Variability in vigour testing of maize (Zea mays L.). Seed Science and Technology. v.23, n.2, p.543-549, 1995.

CAMPOS, V. C. Metodologia do teste de frio para avaliação da qualidade fisiológica de sementes de arroz irrigado. Pelotas, 1998. 63 p. Tese (Doutorado) - Universidade Federal de Pelotas.

CARDOSO, J. E. Podridões radiculares. In: SARTORATO, A.; RAVA, C. A. Principais doenças do feijoeiro comum e seu controle. Brasilia: EMBRAPA,SPI, 1994. p.151-164. 
CARVALHO, N. M. Vigor de sementes. In: CICERO, S. M; MARCOS FILHO, J.; SILVA, W. R. (Coord.) Atualização em produção de sementes. Campinas: Fundação Cargill, 1986. p. 207-223.

CARVALHO, N. M.; NAKAGAWA, J. Sementes : ciência, tecnologia e produção. Campinas: Fundação Cargill, 1988. 429 p.

CICERO, S. M.; VIEIRA, R. D. Teste de frio. In: VIEIRA, R. D.; CARVALHO, N. M. (Ed.) Testes de vigor em sementes. Jaboticabal: FUNEP, 1994. p. 151-164.

CICERO, S. M.; CHAMMA, H. M. C. P.; MORAES, M. H. D. Tratamento fungicida em sementes de milho: relatório técnico. Piracicaba: ESALQ, Departamento de Agricultura, 1989. $14 \mathrm{p}$.

CROCKER, W.; GROVES, J. F. A method for prophesying the life duration of seed. Proceedings National of the Academy of Science, v.1, p.152-155, 1915.

CROSIER, W. F. Fungi envolved and methods of conducting cold tests. Proceedings of the Association of Official Seed Analysts, v.47, p.185-190, 1957.

DELOUCHE, J. C. An accelerated aging technique for predicting relative storability of crimson clover and tall fescue seed lots. Agronomy Abstracts, v.40, 1965.

DIAS, D. C. F. S. Testes de condutividade elétrica e de lixiviação de potássio para avaliação do vigor de sementes de soja (Glycine max (L.) Merril). Piracicaba, 1994. 136 p. Tese (Doutorado) Escola Superior de Agricultura "Luiz de Queiroz", Universidade de São Paulo.

EGLI, D. B.; TEKRONY, D. M.; WIRALAGA, R. A. Effect of soybean seed vigour and size on seedling growth. Journal of Seed Technology, v.14, p.1-12, 1990. 
FERRISS, R. S. ; BAKER, J. M. Relationships between soybean seed quality and performance in soil. Seed Science and Technology, v.18, n.1, p.51-73, 1990.

FIALA, F. Cold test. In: PERRY, D.A. (Ed.) Handbook of vigour test methods. Zürich: ISTA, 1981. p. 28-36.

FIALA, F. Report of the Vigour Test Comittee 1983-1986. Seed Science and Technology, v.15, p.507-522, 1987.

FRATIN, P. Comparação entre métodos para a avaliação da qualidade fisiológica de sementes de milho (Zea mays L.). Piracicaba, 1987. 191 p. Dissertação (Mestrado) Escola Superior de Agricultura "Luiz de Queiroz “, Universidade de São Paulo.

GRABE, D. F. Components of seed vigour and their effects o plant groth and yield. Seed World, v.111, n. 7, p. 4-9, 1973.

GRABE, D. F. Measurement of seed vigour. Journal of Seed Technology, v.1, n.2, p. 18-31, 1976.

HAMPTON, J. G.; JOHNSTONE, K. A.; Bulk conductivity test variables for mungbean, soybean and Frenh bean seeds lots. Seed Science and Technology, v.20, n.3, p. 677-686, 1992.

HARMAN, G. E.; NEDROW, B. L.; CLARK, B. E.; MATTICK, L. R. Associationof volatile aldehyde production during germination with poor soybean and pea seed quality. Crop Science, v.22, p.712-716, 1982.

HELMER, J. D.; DELOUCHE, J. C.; LIENHARD, M. Some indices of vigour and deterioration in seed of crimson clover. Proceedings Association Official of Seed Analysts, v. 52, p. 154-161, 1962. 
HEPBURN, H. A.; POWELL, A. A.; MATTHEWS, S. Problems associet with the routine application of electrical conductivity measurements of individual seeds in the germination testing of peas and soybeans. Seed Science and Technology, v.12, n. 2, p. $403-413,1984$.

IBRAHIM, A.; TEKRONY, D. M; EGLI, D. B. Accelerated ageing techniques for evaluating sorghum seed vigour. Journal of Seed Technology, v.17, p.29-37, 1994.

INTERNATIONAL SEED TESTING ASSOCIATION. Handbook of vigour test methods. 3.ed. Zurich, 1995a. 117 p.

INTERNATIONAL SEED TESTING ASSOCIATION. Handbook of vigour testing seminar. Proceedings, Copenhagen, 1995b. 97 p.

ISELY, D. Vigour Tests. Procedings of Association os Official Seed Analysts. v.47, p. 176-182, 1957.

KRZYZANOWSKI, F. C.; FRANÇA NETO, J. B. Situação atual do uso de testes de vigor como rotina em programas de sementes no Brasil. Informativo ABRATES, v.1, n.3, p. $42-53,1991$ a.

KRZYZANOWSKI, F. C.; FRANÇA NETO, J. B.; HENNING, A. A. Relato dos testes de vigor disponiveis para grandes culturas. Informativo ABRATES, v. 1, n.2, p. 15$50,1991 b$.

LOEFFLER, T. M.; MEYER, J. L.; BURRIS, J. S. Comparision of two test procedures for use in maize drying studies. Seed Science and Technology, v.13, n.3, p. 653$658,1985$. 
LOEFFLER, T. M. TEKRONY, D. M; EGLI, D. B. The bulk conductivity test as na indicator of soybean seed quality. Journal of Seed Technology, v.12, n. 1, p. 37-53, 1988.

LUCENA, E. M. P. Método alternativo para avliação do vigor de sementes de Feijão vagem (Phaseolus vulgaris L.). Viçosa, 1995. 66 p. Dissertação (Mestrado) Universidade Federal de Viçosa.

MARCOS FILHO, J. Envelhecimento Acelerado. In: VIEIRA, R. D.; CARVALHO, N. M. (Ed.) Testes de vigor em sementes. Jaboticabal: FUNEP, 1994. p. 133-150.

MARCOS FILHO, J.; CICERO, S. M; SILVA, W. R. Avaliação da qualidade das sementes. Piracicaba: FEALQ, 1987. 230 p.

MARCOS FILHO, J.; CARVALHO, R. V.; CICERO, S. M.; et al. Qualidade fisiológica e comportamento de sementes de soja (Glycine max (L) Merrill) no armazenamento e no campo. Anais da Escola Superior de Agricultura "Luiz de Queiroz", v.42, p. $195-249,1985$.

MARCOS FILHO, J; PESCARIN, H. M. C.; KOMATSU, T. H.; et al. Testes para avaliação do vigor de sementes de soja e suas relações com a emergência das plântulas em campo. Pesquisa Agropecuária Brasileira, v.19, n.5, p. 605-613, 1984.

MARCOS FILHO, J.; SILVA, A. E.; CICERO, S. M. et al. Efeitos do tamanho da semente sobre a germinação, o vigor e a produção do milho (Zea mays, L.). Anais da Escola Superior de Agricultura “Luiz de Queiroz", v.34, p. 327-337, 1977.

MATTHEWS, S. Evaluation of techniques for germination and vigour studies. Seed Science and Technology, v.9, p. 543-551, 1981. 
MATTHEWS, S. Physiology of seed ageing. Outlook of Agriculture. v.14, n.2, p. 8994, 1985.

McDONALD, Jr, M. B. A review and evoluation of seed vigour tests. Proceedings of the Association of Official Seed Analysts, v.65, p. 109-139, 1975.

MOLINA, J. C. ; IRIGON, D. L. ; ZONTA, E. P. Comparação entre metodologias do teste de frio na avaliação da qualidade fisiológica de sementes de milho (Zea mays L.). Revista Brasileira de Sementes, v.9, n.3, p. 77-85, 1987.

MORENO, J. C. M. Avaliação de testes de vigor em milho e suas relações com a emergência em campo. Pelotas, 1986. 76 p. Dissertação (Mestrado) - Universidade Federal de Pelotas.

MOTTA, C. A. P. Comparação de testes de vigor em sementes de soja com a emergência das plântulas em campo. Pelotas, 1986. 90 p. Dissertação (Mestrado) Universidade Federal de Pelotas.

NAKAGAWA, J. Testes de vigor baseado na avaliação das plântulas. In: VIEIRA, R. D.; CARVALHO, N. M. (Ed.) Testes de vigor em sementes. Jaboticabal: FUNEP, 1994. p. 49-85.

NASCIMENTO, W. M.; CICERO, S. M. Qualidade de sementes de ervilha tratadas com fungicida. II. Qualidade fisiológica. Revista Brasileira de Sementes, v.13, n.1, p. 13-19, 1991.

NEEGARD, P. Seed pathology. London: Mac Millan Press, 1977. 1187 p.

NIJENSTEIN, J. H. Effects of some factors influencing cold test germination of maize. Seed Science and Technology, v.14, p. 313-326, 1985. 
NIJENSTEIN, J. H. Soil cold test - Europear Perspective. In: SEED VIGOUR TESTING SEMINAR, Copenhagem, 1995. Proceedings. p. 34-49.

PERRY, D. A. Report of the vigour test comittee 1977-1980. Seed Science and Technology, v.9, p. 115-126, 1981.

POLLOCK, B. M.; ROOS, E. E. Seed na seedling vigour. In: KOZLOWSKI, T. T. (Ed.) Seed biology, New York: Academic Press, 1972. cap.6, p. 314-388.

POLLOCK, B.M. TOOLE, V. K. Imbibition period as the critical temperature sensitive stage in germination of lima bean seeds. Plant physiology, v.41, p.221-229, 1966.

POPINIGIS, F. Fisiologia da sementes. 2. ed. Brasilia: AGIPLAN, 1985. 289 p.

RODRIGUES, V. L. F. Comparação de testes de vigor para a avaliação da qualidade fisiológica de sementes de feijão vagem (Phaseolus vulgaris, L). Viçosa, 1995. 50 p. Dissertação (Mestrado) - Universidade Federal de Viçosa.

SNEH, B.; KATAN, J.; HENIS, Y.; et al. Methods for evaluating inoculum density of Rhizoctonia in naturally infected soil. Phytopathology, v.56, p. 74-78, 1966.

SILVA, W. R.; MARCOS FILHO, J. Efeitos do peso e do tamanho das sementes de milho sobre a germinação e o vigor em laboratório. Revista Brasileira de Sementes, v.1, n.1, p. 39-52, 1979.

TAO, K. J. Effects of soil water holding capacity o the cold test for soybeans. Crop Science, v.18, n.2, p. 979-982, 1978a.

TAO, J. K. Factors causing variations in the conductivity test for soybeans seed. Journal of Seed Technology, v.3, n.1, p. 10-18, 1978b. 
TEKRONY, D. M. Seed vigour testing - 1982. Journal of Seed Technology, v.8, n.1, p. $55-60,1983$.

TEKRONY, D. M; EGLI, D. B.; WICKMAM, D. A. Effect of corn seed vigour on notillage field performance: field emergence and stand. Crop Science, v.29, p.1525$1528,1989$.

THRONEBERRY, G. O.; SMITH, F. G. Relation of respiratory and enzimatic activity to corn seed viabity. Plant Physiology, v.30, n.4. p. 337-343, 1955.

TOMER, R. P. S.; MAGUIRE, J. D. Seed vigour studies in wheat. Seed Science and Technology, v.18, p.383-392, 1990.

TOMES, L. J.; TEKRONY, D. M.; EGLI, D. B. Factors influencing the tray accelerated ageing test for soybean seed. Journal of Seed Technology, v. 12, p.37-53, 1988.

WAES, J. V. The use of cold test to predict field emergence of maize in official variety trials in Belgium. Seed Science and Technology, v.23, n. 1, p. 21 1-224, 1995.

WASSINK, H., HOEFMAN, R. The factor van de ligging. Boerdery, v.77, n.25, p.27, 1992.

WATERS, L.; BLANCHETTE, L. B. Prediction of sweet corn field emergence by conductivity and cold tests. Journal of the American Society for Hoticultural Science. v. 108, n.5, p.778-781, 1983.

WOLTZ, J. M. Prospects for the standardization of the cold test for corn seed. Lexington, 1997. 104p. Thesis (M. S.) - University of Kentucky. 
WONG, D. H.; BARBETTI, M. J.; SIVASITHAMPARAM, K. Effects of soil temperature and moistureon the patogenicity of fungi associated with roor rot of subterranean clover. Australian Journal of Agricultural Research, v.35, p.675$684,1984$.

WOODSTOCK, L. W. Physiological and biochemical tests for seed vigour. Seed Science and Technology, v.1, p.127-157, 1973.

VANZOLINI, S.; MARTINELLI, A.; SILVA, J. B. C.; et al. Efeitos do periodo de exposição e da temperatura no teste de envelhecimento acelerado para sementes de amendoim (Arachis hypogaea) cultivar Botucatu. In: CONGRESSO BRASILEIRO DE SEMENTES, 10., Foz do Iguaçu, 1997. Resumos. Campinas: ABRATES, 1997. p. 164 .

VIEIRA, R. D.; CARVALHO, N. M.; SADER, R. Testes de vigor e suas possibilidade de uso. In: VIEIRA, R. D; CARVALHO, N. M. Testes de vigor em sementes., Jaboticabal: FUNEP 1994. p. 31 - 47. 